\title{
Tracking the emission and transport of pollution from wildfires using the IASI CO retrievals: analysis of the summer 2007 Greek fires
}

\author{
S. Turquety ${ }^{1, *}$, D. Hurtmans ${ }^{2}$, J. Hadji-Lazaro ${ }^{1}$, P.-F. Coheur ${ }^{2}$, C. Clerbaux ${ }^{1,2}$, D. Josset ${ }^{1}$, and C. Tsamalis ${ }^{1}$ \\ ${ }^{1}$ UPMC Univ. Paris 06; Université Versailles St.-Quentin; CNRS/INSU, LATMOS-IPSL, Paris, France \\ ${ }^{2}$ Spectroscopie de l'atmosphère, Chimie Quantique et Photophysique, Université Libre de Bruxelles, Brussels, Belgium \\ * now at: Laboratoire de Météorologie Dynamique/IPSL, UPMC Univ. Paris 06, Paris, France
}

Received: 16 February 2009 - Published in Atmos. Chem. Phys. Discuss.: 20 March 2009

Revised: 2 July 2009 - Accepted: 14 July 2009 - Published: 24 July 2009

\begin{abstract}
In this paper, we analyze the performance of the Infrared Atmospheric Sounding Interferometer (IASI), launched in October 2006 on board METOP-A, for the monitoring of carbon monoxide (CO) during extreme fire events, focusing on the record-breaking fires which devastated thousands of square kilometers of forest in Greece during the last week (23-30) of August 2007. After an assessment of the quality of the profiles retrieved using the Fast Optimal Retrievals on Layers for IASI (FORLI) algorithm, the information provided on fire emissions and subsequent pollution outflow is discussed. Large $\mathrm{CO}$ plumes were observed above the Mediterranean Basin and North Africa, with total CO columns exceeding $24 \times 10^{18}$ molecules $/ \mathrm{cm}^{2}$ and absolute volume mixing ratios up to 4 ppmv on the 25 August. Up to $30 \times 10^{18}$ molecules $/ \mathrm{cm}^{2}$ and $22 \mathrm{ppmv}$ in the lower troposphere are retrieved close to the fires above the Peloponnese, but with larger uncertainty. The average root-mean-square (RMS) difference between simulated and observed spectra is close to the estimated radiometric noise level, slightly increasing (by $\sim 14 \%$ ) in the fresh fire plumes. CO profiles are retrieved with a vertical resolution of about $8 \mathrm{~km}$, with $\sim 1.7$ pieces of independent information on the vertical in the region considered and a maximum sensitivity in the free troposphere $(\sim 4-5 \mathrm{~km})$. Using the integrated total amount, the increase in $\mathrm{CO}$ burden due to these fires is estimated to $0.321 \mathrm{Tg}, \sim 40 \%$ of the total annual anthropogenic emissions in Greece. The patterns of these $\mathrm{CO}$ enhance-
\end{abstract}

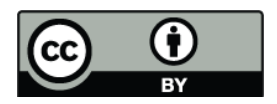

Correspondence to: S. Turquety (solene.turquety@1md.polytechnique.fr) ments are in good agreement with the aerosol optical depth (AOD) retrieved from the MODIS measurements, highlighting a rapid transport of trace gases and aerosols across the Mediterranean Basin (less than one day). While the coarse vertical resolution will not allow the location of the exact plume height, the large $\mathrm{CO}$ enhancements observed in the lower troposphere are consistent with the maximum aerosol backscatter coefficient at $\sim 2 \mathrm{~km}$ detected by the CALIPSO lidar in space (CALIOP).

\section{Introduction}

In addition to being devastating for local ecosystems and economies, wildfires significantly alter air quality, sometimes on regional to hemispheric scales, and are an important component of the climate system. Biomass burning is, indeed, now recognized to be a major contribution to the global emissions of trace gases and aerosols, not only in the tropics but also in the Northern Hemisphere (e.g. Andreae and Merlet, 2001). Several studies have highlighted the importance of emissions from wildfires in the boreal regions of the Northern Hemisphere (e.g. Kasischke et al., 2005). Often burning for several weeks, they constitute extremely large perturbations (e.g. Turquety et al., 2007), which can increase the background level of relatively long lived species on hemispheric scales and explain most of the interannual variability in the surface observations (e.g. Wotawa et al., 2001; Szopa et al., 2007). In the mid-latitudes, wildfires, mainly accidental or criminal fires, are often burning close to inhabited regions, and efforts are deployed to rapidly control

Published by Copernicus Publications on behalf of the European Geosciences Union. 
them. But they remain critical for regional air quality. On average for the 2000-2006 time period, biomass burning contributed to $\sim 5 \mathrm{Tg}$ of $\mathrm{CO}$ per year in Europe according to the widely used Global Fire Emissions Database (GFED) version 2 (van der Werf et al., 2006). This appears to be small compared to the estimated total of $\sim 82 \mathrm{Tg} /$ year emitted by anthropogenic activities in the same region according to the EDGAR 3.2 FT2000 inventory (Olivier and Berdowski, 2001). However, since more than $70 \%$ of the burning occurs between June and September, their impact becomes critical during the summer.

Southern Europe and the Mediterranean basin are regularly affected by forest fires which can burn thousands of hectares in a few days. The summer of 2007 was among the worst fire seasons of the past decades in Europe. Figure 1 shows the number of fire hotspots detected from space by the ESA Along-Track Scanning Radiometer (ATSR) World Fire Atlas (Arino et al., 2007). Fires were most severe in Greece, with a total of $3138 \mathrm{~km}^{2}$ burned according to the provisional data from the European Commission Joint Research Center (JRC) (EFFIS Forest Fires in Europe 2007 report, 2008). The largest fires burned at the end of August in the Peloponnese ( 5 fires burned $\sim 1700 \mathrm{~km}^{2}$ ) and in Euboea, North of Athens ( 2 fires burned $\sim 250 \mathrm{~km}^{2}$ ). Although the number of fires was similar to previous years, the severity of the burning events was much larger due to several heat waves in the preceding weeks, extended droughts and strong winds. With the expected increase of such hot and dry episodes as a result of climate change (Schär et al., 2004; Meehl and Tebaldi, 2004), it becomes urgent to better evaluate and account for wildfire emissions in the analyses of air quality and regional climate change.

The location of the fires (hotspots) is monitored by several space-borne remote sensors, e.g. ATSR (Arino et al., 2007) and the MODerate resolution Imaging Spectroradiometer (MODIS, Justice et al., 2002). Nevertheless, the extent of the areas which actually burned remains subject to large uncertainties (e.g. Giglio et al., 2006), the corresponding emissions are difficult to evaluate accurately (e.g. Kasischke and Penner, 2004) and the vertical transport processes above these large sources are not well understood. These are all critical parameters for the simulation of the impact of wildfires by chemistry and transport models that need to be better understood (e.g. Turquety et al., 2007; Damoah et al., 2006; Fromm and Servranckx, 2003).

Atmospheric observations of trace gases and aerosols in the fire plumes are necessary to evaluate model simulations of their effects and, eventually, infer top-down corrections on emissions inventories (e.g. Henze et al., 2004; Pfister et al., 2005; Arellano et al., 2006). Space-based observations are particularly valuable since they allow the monitoring of pollution transport with good spatial and temporal resolution. However, in order to have confidence in these top-down constraints, it is absolutely crucial to have good knowledge of the quality of the observations used. But validation exercises

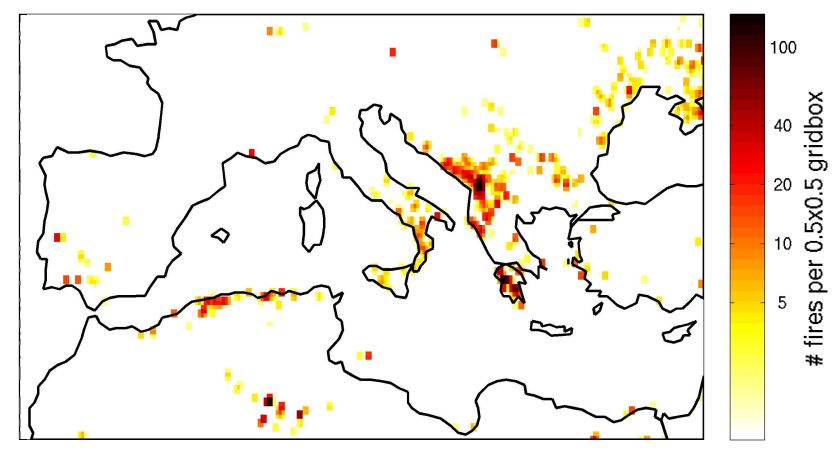

Fig. 1. Fire hotspots detected by the AATSR satellite instrument during the summer of 2007 (July-August) summed over a $0.5^{\circ} \times 0.5^{\circ}$ grid .

based on the available surface or in situ observations are often representative of background conditions and are rarely located within pollution plumes, and precise information on the performance of the retrievals in highly polluted conditions is not provided. In this paper, we analyze the performance of the Infrared Atmospheric Sounding Interferometer (IASI) for the monitoring of the emission and transport of carbon monoxide $(\mathrm{CO})$ in such highly polluted conditions. Therefore, we focus our analysis on the large Greek fire event at the end of August 2007.

With a lifetime of the order of several weeks in the free troposphere, $\mathrm{CO}$ is one of the main tracers of long-range transport of pollution. It is produced as a result of incomplete combustion and the oxidation of methane and non-methane hydrocarbons (NMHC) and is principally removed by reaction with $\mathrm{OH}$. It is currently regulated by air quality standards worldwide as a major ozone precursor. It also contributes to climate change through its effect on ozone and methane chemistry. It is observed by several satellite borne instruments either from measurements in the thermal infrared (IR) or in the near-IR spectral range (e.g. Turquety et al., 2008). The most recent is IASI, launched in October 2006 on board the first of the three successive METOP satellites (METOPA) which will provide 15 years of consistent measurements. IASI is a nadir-looking high resolution IR sounder developed by CNES in collaboration with EUMETSAT for an accurate observation of temperature and water vapor, aiming at improving operational weather forecasting. It also allows the monitoring of several IR absorbing species, summarized in Clerbaux et al. (2009), in particular CO discussed in this paper and evaluated on a global scale in George et al. (2009). One of the most important improvements compared to other existing IR sounders is the excellent horizontal coverage allowed by its across-track swath width of $2200 \mathrm{~km}$ providing twice daily global coverage.

Signatures from biomass burning are one of the main features of the global $\mathrm{CO}$ distributions observed from space (e.g. Lamarque et al., 2003; Edwards et al., 2004; Turquety et al., 
2007; McMillan et al., 2008; Yurganov et al., 2008), both due to the large $\mathrm{CO}$ concentrations resulting from these fires and to the fact that the fire plumes are often rapidly transported toward the free troposphere, where the IR remote sensors are the most sensitive (e.g. Turquety et al., 2007, 2008). Here, we discuss the performance of the IASI CO retrieval in such extreme pollution cases. After a general description of the Fast Optimal Retrievals on Layers for IASI (FORLI) algorithm, we evaluate its performance for the study of fire plume events. We then discuss the information provided on the corresponding emissions and subsequent transport of pollution. Therefore, we explore the correlations between $\mathrm{CO}$ and aerosols in these plumes based on the MODIS aerosol optical depth (AOD), widely used for the monitoring of fire smoke, and the vertical soundings from the Cloud-Aerosol Lidar with Orthogonal Polarization (CALIOP) on board CALIPSO (Cloud Aerosol Lidar and Infrared Pathfinder Satellite Observations). These comparisons will allow a combined analysis of the transport pathways of trace gases and aerosols, as well as an evaluation of the information provided by IASI on plume height. This study will be a first step towards an analysis of the interactions between aerosols and photochemistry.

\section{IASI CO retrieval}

\subsection{IASI observations and forward problem}

IASI is recording IR spectra with a spectral resolution of $0.5 \mathrm{~cm}^{-1}$ apodized, sampled at $0.25 \mathrm{~cm}^{-1}$, extending from 645 to $2760 \mathrm{~cm}^{-1}$. In addition, its low radiometric noise, estimated before launch to $0.2-0.35 \mathrm{~K}$ noise equivalent delta temperature (NeDT), slightly improved on flight, allows the retrieval of a series of IR absorbing species (Clerbaux et al., 2009). 120 spectra are recorded along each swath, allowing global coverage twice daily (Sun synchronous orbit with a 09:30 equator local crossing time for the ascending node), with a small field of view of $2 \times 2$ circular pixels, each of $12 \mathrm{~km}$ footprint diameter at nadir.

IASI spectra may be simulated using radiative transfer equations, modeled by a direct function $F$ (forward model in the following), so that the measurement vector $\boldsymbol{y}$ may be written:

$\boldsymbol{y}=F(\boldsymbol{x}, \boldsymbol{b})$.

The parameter $\boldsymbol{x}$ corresponds to the state of the atmosphere (state vector) which will be more specifically analyzed, and $\boldsymbol{b}$ groups all other parameters which will influence the IR radiation: meteorological and chemical information on the state of the atmosphere (other than $\boldsymbol{x}$ ), plus the spectroscopic database and the instrumental characteristics. In the inverse problem, $\boldsymbol{x}$ becomes the retrieved parameters, and $\boldsymbol{b}$ the "fixed" parameters.

A specific software has been developed at Université Libre de Bruxelles (ULB) to handle as fast as possible all the
IASI spectra. It is based on the Atmosphit code (e.g. Coheur et al., 2005) and uses appropriate approximations and precomputed look-up tables (LUT). Running on 76 CPUs it is able to handle a whole day of data in about $1 \mathrm{~h}$ using the operational Eumetcast Level 2 temperature and humidity profiles. The code can accommodate temperature and humidity profiles coming from various sources/models.

In the thermal IR, $\mathrm{CO}$ absorbs radiation in the 1-0 rotationvibration band centered at $4.7 \mu \mathrm{m}\left(2128 \mathrm{~cm}^{-1}\right)$, which is clearly visible by IASI in the $2050-2190 \mathrm{~cm}^{-1}$ spectral region (see Fig. 2). The main interfering trace gases in this spectral range are $\mathrm{H}_{2} \mathrm{O}, \mathrm{N}_{2} \mathrm{O}, \mathrm{O}_{3}$ and $\mathrm{CO}_{2}$, but the $\mathrm{CO}$ signal is dominant for most of the band, and is observed at all times and all latitudes (except over Antarctica where the signal can become too low - these data are filtered out). The residual between the forward calculation and the actual IASI measurement is used to adjust the $\mathrm{CO}$ profiles in the retrieval process (see following section).

\subsection{Retrieval algorithm}

The FORLI-CO software used for our retrieval of CO vertical profiles is based on the optimal estimation method (OEM) described by Rodgers (2000). It minimizes the difference between the observation and simulation by iteratively updating the state vector (set of unknown parameters). Since more than one solution could fit the observations (ill-posed problem), it is necessary to constrain the results with a priori information containing both the averaged value expected, $\boldsymbol{x}_{a}$, and allowed variability around this average given by a covariance matrix $\mathbf{S}_{a}$. The OEM then gives the optimal solution for the state vector $\boldsymbol{x}$ to be retrieved, given a measurement $\boldsymbol{y}$, with error covariance $\mathbf{S}_{\varepsilon}$, and a forward model $\hat{\boldsymbol{y}}=F(\boldsymbol{x})$. The solution can be found by iteratively applying:

$\hat{\boldsymbol{x}}_{i+1}=\boldsymbol{x}_{a}+\mathbf{D}_{y}\left[\boldsymbol{y}-F\left(\hat{\boldsymbol{x}}_{i}\right)-\mathbf{K}_{i}\left(\boldsymbol{x}_{a}-\hat{\boldsymbol{x}}_{i}\right)\right]$

with

$\mathbf{D}_{y}=\hat{\mathbf{S}}_{i} \mathbf{K}_{i}^{T} \mathbf{S}_{\varepsilon}^{-1} \quad$ and $\quad \hat{\mathbf{S}}_{i+1}=\left(\mathbf{K}_{i+1}^{T} \mathbf{S}_{\varepsilon}^{-1} \mathbf{K}_{i+1}+\mathbf{S}_{a}^{-1}\right)^{-1}$

where $\mathbf{K}_{i}=(\partial F / \partial \boldsymbol{x})_{i}$ is the Jacobian at state $\boldsymbol{x}_{i}, \mathbf{K}_{i}^{T}$ is its transpose, and $\hat{\boldsymbol{x}}_{i+1}$ is the updated state vector. The matrix $\mathbf{D}_{\boldsymbol{y}}$ is known as the matrix of contribution functions. The error covariance of the solution is given by $\hat{\mathbf{S}}_{i+1}$. The iteration starts with some initial estimate of the state, chosen to be the a priori information $\boldsymbol{x}_{a}$, of covariance $\mathbf{S}_{a}$, and terminates when convergence has been reached (less than seven iterations typically required).

The retrieval error is the sum of three main components:

$\hat{\boldsymbol{x}}-\boldsymbol{x}=(\mathbf{I}-\mathbf{A})\left(\boldsymbol{x}-\boldsymbol{x}_{a}\right)+\mathbf{G} \varepsilon+\mathbf{G K}_{\boldsymbol{b}}(\boldsymbol{b}-\hat{\boldsymbol{b}})$,

with $\mathbf{A}=\partial \hat{\boldsymbol{x}} / \partial \boldsymbol{x}=\mathbf{G K}$, the averaging kernel matrix characterizing the sensitivity of the retrieval to the true profile, and $\mathbf{K}_{\boldsymbol{b}}=\partial F / \partial \boldsymbol{b}$, the sensitivity of the radiative transfer to the parameters $b$. In Eq. (3), the first term then represents a 


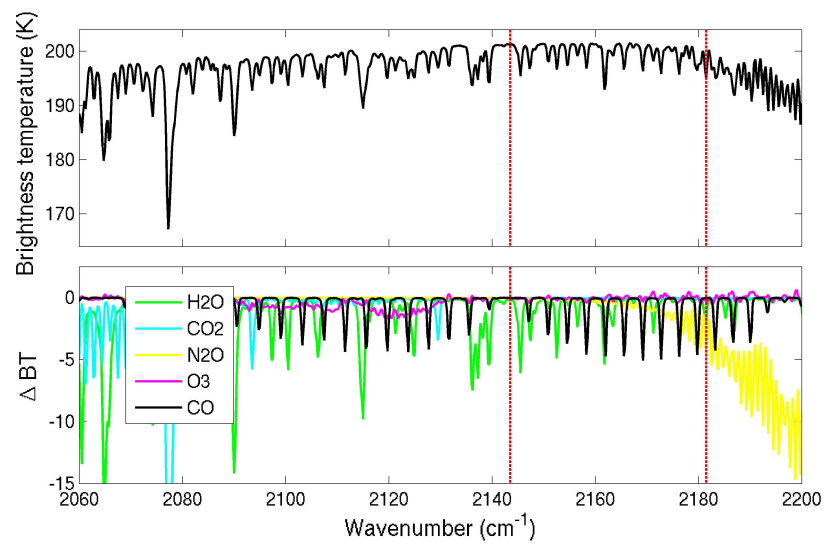

Fig. 2. Example of IASI spectrum simulation (in brightness temperature) around the $\mathrm{CO}$ absorption band for a standard atmosphere and average $\mathrm{CO}$ profile (top panel). The signatures from the main absorbing species in this spectral region are shown in the bottom panel in brightness temperature difference. The limits of the region used for the $\mathrm{CO}$ retrieval are highlighted in red.

"smoothing" error, due to the lack of vertical sensitivity of the instrument, the second term is the measurement error and the third one is the model parameters error. The smoothing error is usually the dominant source of uncertainty for $\mathrm{CO}$ retrieval (Barret et al., 2005). The measurement error and the error due to the temperature profile are typically twice lower than the smoothing error and of the same order of magnitude. Note however that error due to the temperature profile may be larger in fire plumes but it is difficult to quantify in the absence of specific in situ observations. In the following, we will therefore discuss primarily the averaging kernels associated with the retrievals to evaluate the smoothing error. They also provide valuable information on the vertical resolution (full width at half maximum) and the number of independent pieces of information in the profiles or degrees of freedom for signal (DOFS):

$$
\text { DOFS }=\text { trace }(\mathbf{A})
$$

As already mentioned, the direct computations of the spectra are based on LUT's that have a spectral oversampling of 10 (e.g. sampling of $2.5 \times 10^{-3} \mathrm{~cm}^{-1}$ ). These tables are pre-computed on a logarithmic grid in pressure $\left(4.5 \times 10^{-5}\right.$ to $1 \mathrm{~atm})$, a linear grid in temperature (162.8 to $322.64 \mathrm{~K})$ and eventually a linear grid in humidity (for water vapor lines), and interpolated on-the-fly.

The radiative transfer includes the influence of the average downward flux from the atmosphere "unabsorbed" by the grey surface and the reflected solar radiance. The latter is essential above the sea surface in situations of sun-glint.

The derivatives with respect to the vertical distribution of species are computed analytically. As the main timeconsuming step of the computations is the convolution by the instrumental lineshape (ILS), the bottleneck of the re- trieval process remains the calculation of the Jacobians $\mathbf{K}_{i}=(\partial F / \partial \boldsymbol{x})_{i}$. In order to avoid any excursion of the profiles in negative concentrations we are working in logarithmic space during the iterative process, the final iteration results being given in the normal units.

The spectral region used for the CO retrieval is limited to the $\mathrm{R}$ branch of the absorption band from 2143 to $2181.25 \mathrm{~cm}^{-1}$. This avoids interferences due to ozone (see Fig. 1) and minimizes the impact of the weak lines from the latter and possibly other absorbing species. However the spectrum is computed between 2128 and $2206 \mathrm{~cm}^{-1}$, also useful to avoid side effects when convoluting by the ILS. The measurement vector $y$ then includes 154 IASI channels. The measurement error covariance matrix $\mathbf{S}_{\boldsymbol{\varepsilon}}$ was chosen to be a diagonal matrix, with elements corresponding to the expected radiometric noise in the spectral region used, $2.00 \times 10^{-9} \mathrm{~W} /\left(\mathrm{cm}^{2} \mathrm{~cm}^{-1} \mathrm{sr}\right.$ ) (Clerbaux et al., 2009).

The a priori was constructed using a database of observations including aircraft profiles during take-off and landing from the MOZAIC (Measurement of OZone and water vapor by AIrbus in-service airCraft) program (Nedelec et al., 2003), and ACE-FTS satellite observations in the upper troposphere and above (Clerbaux et al., 2005), complemented with distributions from the LMDz-INCA global model (Turquety et al., 2008) in order to have a matrix representative of both background and polluted conditions. The a priori error (square root of the variance, i.e. diagonal of the covariance matrix) reaches a maximum at the first level $(0-1 \mathrm{~km})$ with a variability of $\sim 65 \%$ around the a priori profile, and decreases progressively to $\sim 35 \%$ in the $4-10 \mathrm{~km}$ levels. It then slightly increases in the upper troposphere/lower stratosphere $(\sim 40 \%)$.

Forward simulation of the IASI radiances requires a reasonable knowledge of the state of the atmosphere, in particular for the surface parameters (temperature, pressure and emissivity) as well as for temperature and water vapor profiles. Since the IASI operational retrievals for water vapor and temperature became available only from October 2007, temperature and humidity profiles from the analysis of the European Centre for Medium-Range Weather Forecasts (ECMWF) are used for the analysis of IASI spectra in summer 2007. These are 6 hourly data from the operational analysis, provided at horizontal resolution $1.125^{\circ} \times 1.125^{\circ}$ and on 21 levels. The analyses are then interpolated to the IASI measurement location and time. The surface temperature is retrieved from the IASI spectra using the atmospheric windows. In addition, surface emissivity from a climatology based on MODIS/Terra satellite observations (Wan, 2008) is used.

Here, the state vector $\boldsymbol{x}$ we are interested in is the CO profile, retrieved on up to 19 levels from the surface to the top of the atmosphere. Additional fitted parameters include a water vapor profile, $\mathrm{CO}_{2}$ and $\mathrm{N}_{2} \mathrm{O}$ total columns as well as surface temperature. Since the IASI field of view allows a good horizontal resolution and sampling, we have chosen to analyze 

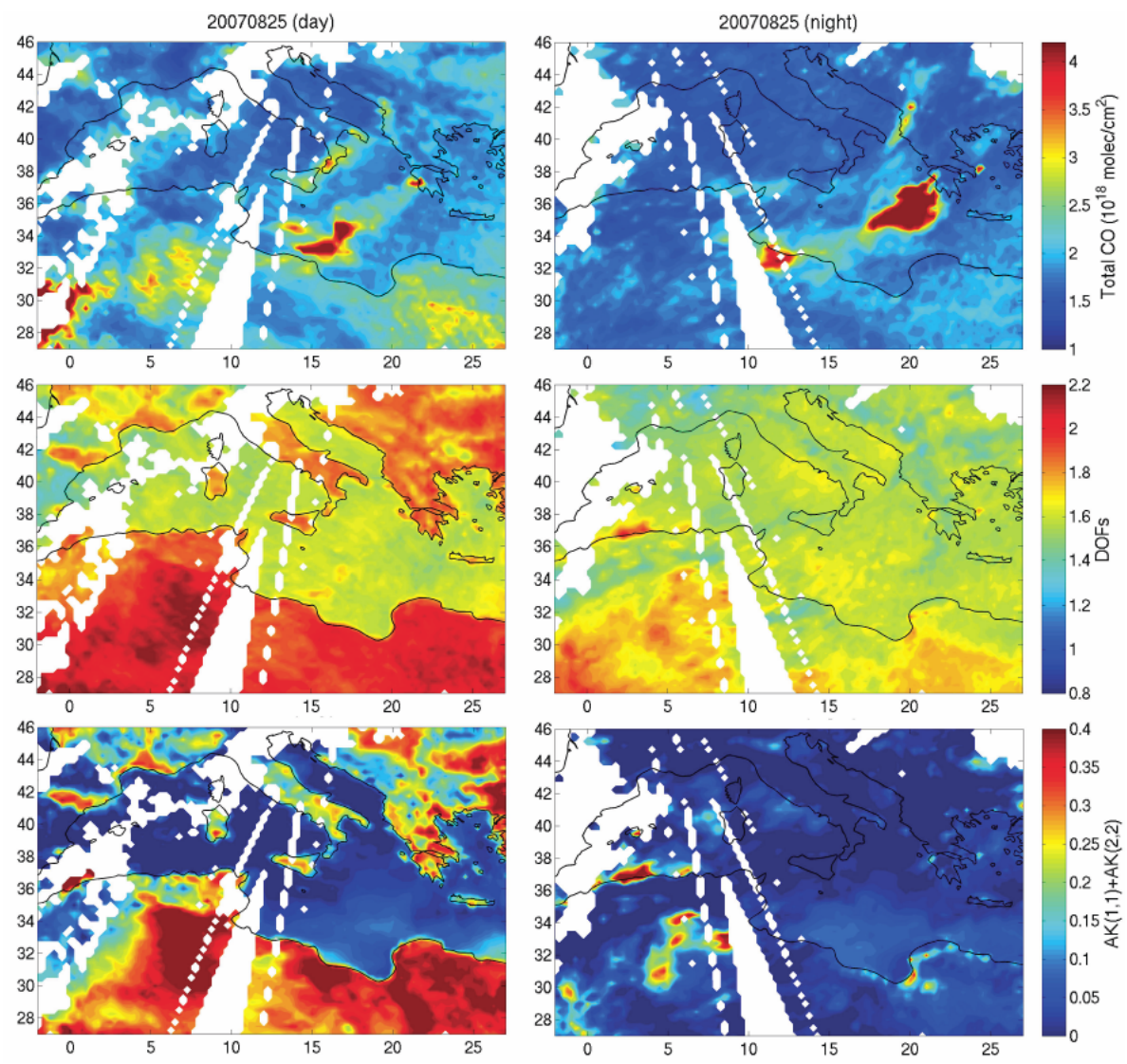

Fig. 3. IASI daytime (left panels) and nighttime (right panels) distributions on 25 August 2007 of the total column of CO retrievals (top panels), the degrees of freedom for signal (DOFS) characterizing the profile retrievals (middle panels), and the contribution from the first two levels to this DOFS (bottom panels), all interpolated on a $0.2^{\circ} \times 0.2^{\circ}$ grid. The white areas correspond to rejected data (mostly cloudy pixels) and regions not sounded by IASI (white triangles to the south of the region correspond to the end of the instrument's swaths for the orbits crossing the region at that time).

only the cloud free pixels, without any cloud clearing in the retrieval. Therefore, a cloud filter based on the comparison of the brightness temperatures at 11 and $12 \mu \mathrm{m}$ (BT11 and BT12) with the skin temperature (Ts) extracted from ECMWF analysis (collocated with IASI measurements) is used. To calculate BT11 and BT12, the average temperatures are estimated for channels in the spectral ranges 900 $905 \mathrm{~cm}^{-1}$ and the $843-845 \mathrm{~cm}^{-1}$, respectively (Hadji-Lazaro et al., 2001). We consider spectra as cloud-free when differences between Ts and BT11 and BT12 are lower than $15 \mathrm{~K}$ in absolute value.

\section{Using IASI CO retrievals to track the long-range transport of pollution from large fires over the Mediterranean basin}

\subsection{Performance of the IASI retrieval in highly polluted conditions}

Figure 3 shows the distribution of the total CO column retrievals (sum of partial columns) for the 25 August 2007, when the largest plume was observed, as well as the corresponding number of independent information on the vertical profile (DOFS, Eq. 4) and the contribution from the lower troposphere to this DOFS. For both daytime and nighttime retrievals, clear enhancements are observed above the regions of fires (Greece, Albany and Italy during the day) as well as above the Mediterranean Basin. Large fire plumes originating from the Greek fires are observed at night over the Central Basin, while emissions from fires in Italy were less efficiently exported. 

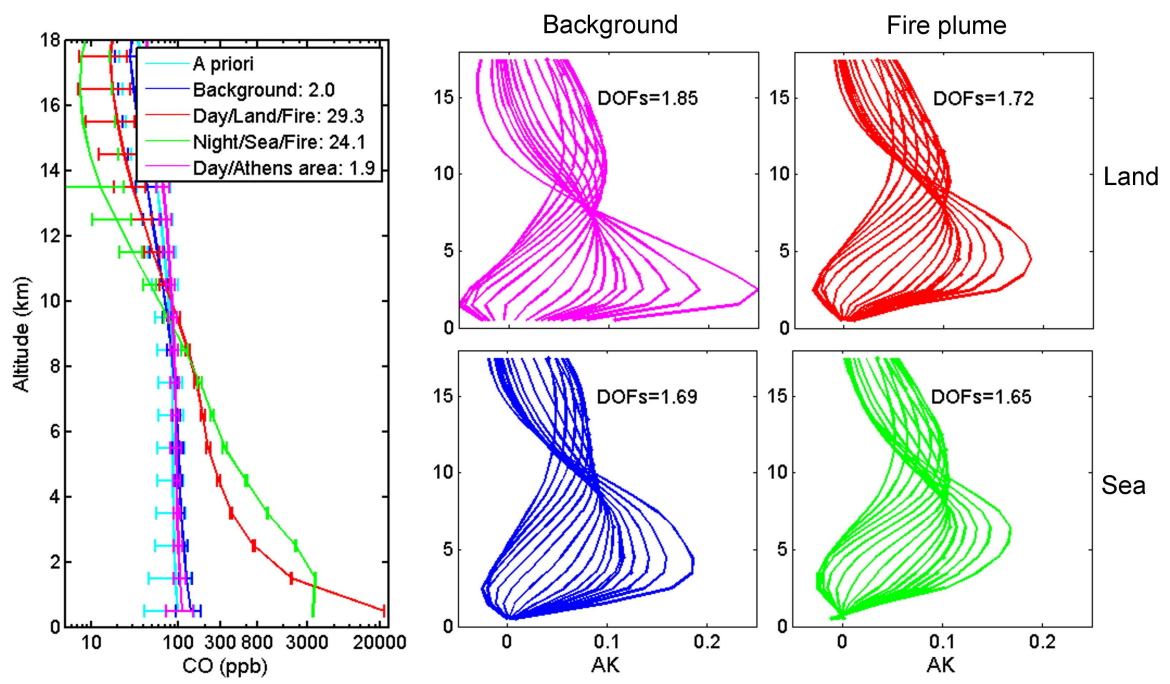

Fig. 4. CO profiles (left panel) retrieved for four different situations: close to emissions above the continent (Peloponnese) during the day, within the plume over the sea during the night, and outside of the plume above land during the day and sea during the night (background). The errorbars correspond to the retrieval error. The cyan line shows the a priori profile and associated error. Note that the CO mixing ratios are reported on a log scale. For each profile, the corresponding total column is given in the legend (in $10^{18}$ molecules $/ \mathrm{cm}^{2}$ ) and the averaging kernels characterizing the retrieval are shown in the right-hand-side (same color code).

For all the days considered, the CO columns outside the fire plumes appear lower above sea than above land during the day, and lower during the night than during the day above land. This is explained by the different thermal contrasts (Clerbaux et al., 2009): the continental surface is significantly warmer than the sea surface, and rapidly cools during the night. This results in higher sensitivity to the lower troposphere during the day above land, while the sensitivity above sea remains similar (Fig. 3). Therefore, we will here always consider daytime and nighttime measurements separately. DOFS vary between $\sim 1.8$ over land during the day in Southern Europe (reaching more than 2 over deserts but with large associated errors) and $\sim 1.6$ over the sea.

Examples of profile retrievals and associated averaging kernels are plotted on Fig. 4 for four different situations, either within the fire plume (at different stages of the transport) or for background conditions. Extremely large CO mixing ratios are found for this event; we measured up to 22 ppmv close to the fires (but subject to large uncertainties as discussed below) and 4 ppmv in the transported plume. The latter is up to two orders of magnitude larger than the a priori and background profiles. As a comparison, Hobbs et al. (2003) reported up to $3.9 \mathrm{ppmv} \mathrm{CO}$ in the fire plumes from in situ measurements close to savanna fires in South Africa. Even though burned vegetations are very different (for example, emission factor for savanna is estimated to $65 \mathrm{~g} \mathrm{CO} / \mathrm{kg}$ dry matter, and to $107 \mathrm{~g} \mathrm{CO} /$ dry matter for extratropical forests, Andreae and Merlet, 2001), these observations show that the extreme concentrations obtained from the IASI data remain realistic in the case of large fires. Such extreme $\mathrm{CO}$ concentrations have, to our best knowledge, never been measured before from satellites.
The averaging kernels for the different selected situations show that the profiles have a vertical resolution of $\sim 8 \mathrm{~km}$. The sensitivity reaches a maximum around $5 \mathrm{~km}$ for all cases, with a secondary peak around $12 \mathrm{~km}$. The sensitivity rapidly decreases towards the surface. Over land, the thermal contrast is usually higher so that the instrument is more sensitive to the first levels (see example in Fig. 4 in the Athens area). Such cut-off of the averaging kernels in the lower troposphere, also visible (but with lower importance) in the fire plume above sea, suggests that CO may still be underestimated in the latter retrievals.

Note that the retrieval error (error bars in Fig. 4), derived from the retrieval error covariance matrix (Eq. 2), does not increase significantly in the fire plumes. For the examples considered, it varies between $36 \mathrm{ppbv}$ above land during the day and $47 \mathrm{ppbv}$ above the sea at night ( $\sim 30 \%$ of background mixing ratios) for the first retrieval level $(0-1 \mathrm{~km})$, and it remains close to $10 \mathrm{ppbv}$ in the free troposphere for all cases ( $\sim 10 \%$ of background mixing ratios). These stable and relatively low errors for the retrievals within the fire plume are somewhat inconsistent with the larger root-meansquare (RMS) error of the differences between observed and fitted spectra (or residuals), plotted in Fig. 5. These highlight larger uncertainty in the fire plumes, especially close to the emissions, with an apparent underestimate of the retrieved $\mathrm{CO}$.

The retrieval error covariance matrix mainly depends on the measurement error and on the a priori covariance matrices, and does not account for two of the main error sources: the smoothing error (associated with the vertical sensitivity) and the errors resulting from uncertainties on surface temperature retrievals and on the temperature profile used. 


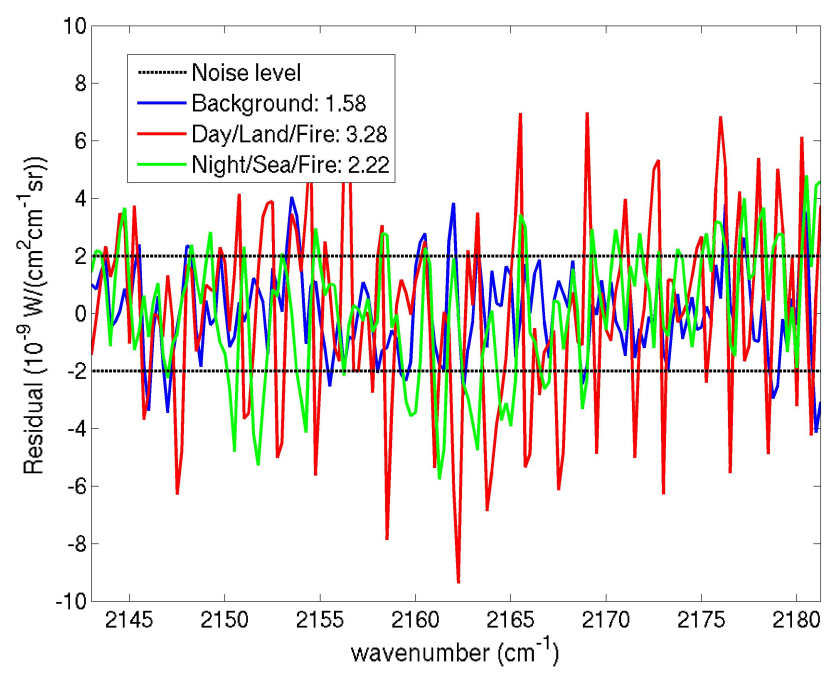

Fig. 5. Examples of residuals (observed - fitted spectra) for the three of the four examples of Fig. 4 (one background and two fire situations: one over land and one over sea). For each example, the corresponding RMS error is indicated in the legend (in $\left.10^{-9} \mathrm{~W} /\left(\mathrm{cm}^{2} \mathrm{~cm}^{-1} \mathrm{sr}\right)\right)$.

Although the averaging kernels show decreasing sensitivity to the lower levels in the fire plumes, the corresponding smoothing error remains close to that estimated for background retrievals (around 30\% for the first level). The fact that the retrieval in highly polluted conditions has such limited sensitivity is still not well understood. Forward simulations show that even in this kind of large pollution events, there is no saturation of the $\mathrm{CO}$ lines. A combination of several factors could explain the largest uncertainties. Enhanced vertical mixing above the fires could lower the thermal contrast, and particular conditions in the fire plumes could induce significantly larger uncertainty of the ancillary parameters used in the inversion. In particular, surface and atmospheric temperatures could be significantly modified close to fires. The large aerosol concentrations in the fire plumes could also impact the retrieval quality, although signature from aerosols remains small in the $\mathrm{CO}$ band. These uncertainties are difficult to evaluate without specific independent observations, ideally from in situ sampling.

Another important aspect is that the extreme cases observed during fire events are not well represented in the a priori covariance matrix $\mathbf{S}_{a}$. This means that the retrieval could be biased towards the a priori, and therefore underestimated. This bias is difficult to quantify, and, again would need to be fully assessed using independent in situ observations. For a first evaluation of the performance of the retrieval, we chose to rely on the RMS of the residuals.

The RMS, as well as the mean differences (bias expressed as a percentage of the total RMS), are given in Fig. 6. The RMS reflects both the error due to radiometric noise (random error, estimated to $\left.2.00 \times 10^{-9} \mathrm{~W} /\left(\mathrm{cm}^{2} \mathrm{~cm}^{-1} \mathrm{sr}\right)\right)$ and due to the forward model parameters ( $\mathrm{CO}$ but also the parameters $b$ in Eq. (1), for instance the temperature and water vapor profiles or aerosol contamination). Such systematic error is expected to result in a bias. Retrievals over land are characterized by higher RMS, especially for daytime measurements due to stronger signal. The largest errors correspond to retrievals over deserts and are likely due to the presence of sand (uncertainties on reflectance and emissivity pattern). In the following, these cases are filtered out by only considering retrievals with $\mathrm{RMS}<3.5 \times 10^{-9} \mathrm{~W} /\left(\mathrm{cm}^{2} \mathrm{~cm}^{-1} \mathrm{sr}\right)$ (a value chosen in order to remove the largest errors while keeping the fire plumes). During the day, this filter removes $40 \%$ of the observations over land and $1 \%$ over sea (in the region considered here), and only $2.5 \%$ and $0.05 \%$ over land and sea, respectively, during the night. Larger RMS is also visible on the West side of the Mediterranean Basin, corresponding to a high bias, which could be explained by contamination of the spectra associated with the transport of Saharan dust. The retrievals in the fire plume, especially those close to the emission region (here the Peloponnese) are also characterized by slightly larger RMS, but associated with a low bias.

The performance in terms of residual during the entire time period (23-30 August 2007) is summarized in Table 1. The overall RMS is $\sim 2 \times 10^{-9} \mathrm{~W} /\left(\mathrm{cm}^{2} \mathrm{~cm}^{-1} \mathrm{sr}\right)$, with less than $3 \%$ due to a bias, which remains very close to the expected radiometric noise. The error is larger over land than over sea both during the day and during the night, and is largest over land during the day. This is mainly explained by the larger error over North Africa, not completely removed by the RMS filter. No correlation was found between RMS and CO amount in the retrieval, showing that the performance is similar in the plumes and in background conditions. However, in the strong enhancements associated with the biomass burning plumes, the RMS tends to be slightly larger $\left(2.3 \times 10^{-9} \mathrm{~W} /\left(\mathrm{cm}^{2} \mathrm{~cm}^{-1} \mathrm{sr}\right)\right)$, and a bias can appear close to the emissions (Figs. 5 and 6).

In order to better understand the sources of uncertainty in the retrievals, four hypotheses have been tested: too low a priori variability for such extreme events; too low noise level for this region; aerosol contamination; inhomogeneity of the IASI pixel. According to the preliminary analyses conducted, the larger RMS is most probably due to increased inhomogeneity in the IASI pixel within the fire plumes. Further studies are required in order to better estimate these inhomogeneities for different situations as well as their impact on the $\mathrm{CO}$ retrievals. The retrievals are also very sensitive to the temperature and water vapor profiles used. A water vapour profile is fitted in order to avoid too large impact of this parameter on the retrievals. However, since our retrieval is based on the ECMWF meteorological fields, uncertainties may remain.

A complementary evaluation of the retrieval error based on independent measurements and on the global scale is performed by George et al. (2009) in a companion paper. In the absence of available coincident in situ observations for this 

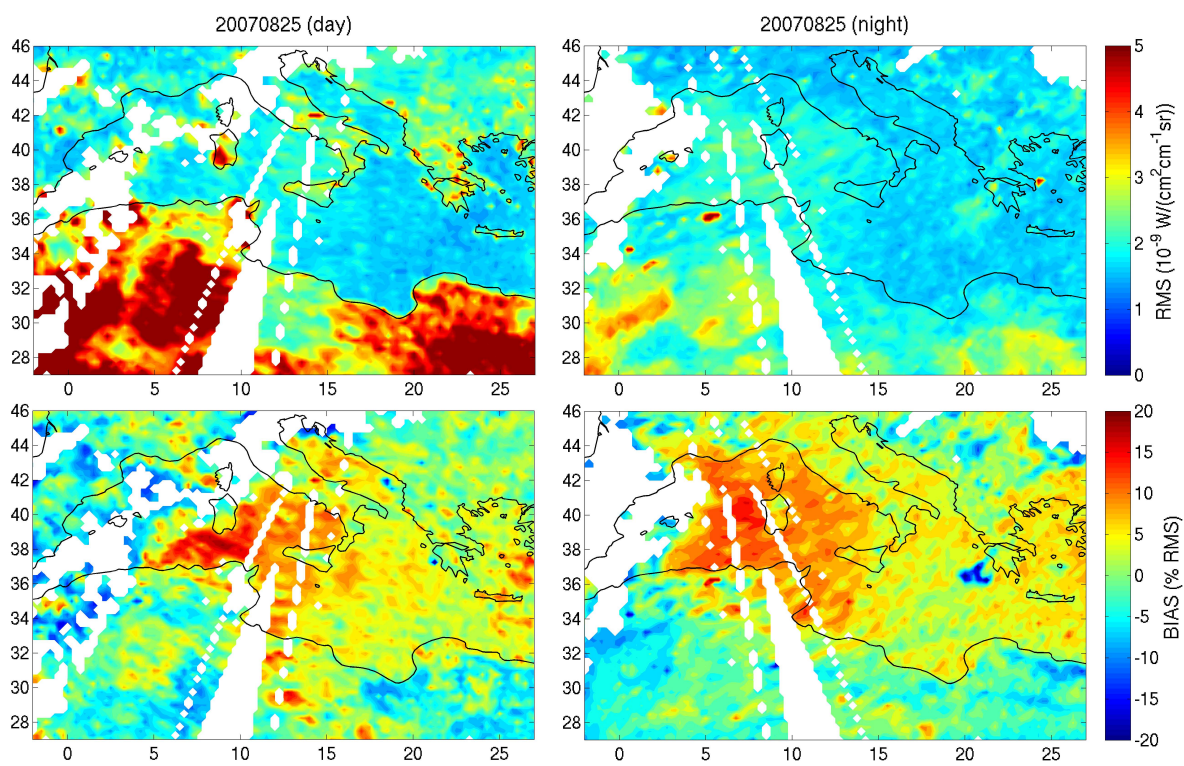

Fig. 6. Same as Fig. 3 but for the RMS error between the observed and the fitted spectrum and the percentage RMS explained by a bias.

Table 1. Summary of the performance of the fit in terms of residual RMS and bias (see text for details). For each case, the average and standard deviation over the region of reference (cf. Fig. 2) is provided.

\begin{tabular}{rlrrr}
\hline & Total CO & RMS & Bias \\
& & $\left(10^{18}\right.$ molecules $\left./ \mathrm{cm}^{2}\right)$ & $\left(10^{-9} \mathrm{~W} /\left(\mathrm{cm}^{2} \mathrm{~cm}^{-1} \mathrm{sr}\right)\right)$ & $(\% \mathrm{RMS})$ \\
\hline \multirow{3}{*}{ Night } & $1.80 \pm 0.34$ & $2.07 \pm 0.52$ & $0.68 \pm 5.15$ \\
& Land & $5.71 \pm 1.39$ & $2.40 \pm 0.58$ & $-2.30 \pm 5.98$ \\
& Plume* & $1.91 \pm 0.86$ & $1.79 \pm 0.27$ & $5.55 \pm 4.34$ \\
& Sea & Plume* & $1.97 \pm 0.3$ & $2.99 \pm 7.43$ \\
& Land & $2.72 \pm 3.73$ & & \\
\multirow{2}{*}{ Day } & Plume* & $4.05 \pm 0.70$ & $2.40 \pm 0.57$ & $1.66 \pm 5.62$ \\
& Sea & $1.93 \pm 0.48$ & $2.80 \pm 0.43$ & $1.42 \pm 5.60$ \\
& Plume* & $4.43 \pm 2.43$ & $1.74 \pm 0.26$ & $5.05 \pm 5.37$ \\
\end{tabular}

* The plume is defined as columns CO exceeding $3 \times 10^{18}$ molecules $/ \mathrm{cm}^{2}$.

time period, we have compared the results over our region of interest with $\mathrm{CO} v 3$ retrievals from the MOPITT/Terra observations in the thermal IR. MOPITT and IASI retrievals have similar characteristics with, in particular, maximum sensitivity in the free troposphere (Deeter et al., 2003). Moreover, overpass times for Terra are close to those of METOP (09:30 equator local crossing time for METOP, 10:30 for Terra), allowing direct comparisons. Results for the 2007 Greek burning event are consistent with the global comparisons between the two CO products (George et al., 2009): while the large-scale patterns are in good general agreement, IASI CO is on average 35\% higher than MOPITT for the elevated CO concentrations (IASI columns larger than $3 \times 10^{18}$ molecules $/ \mathrm{cm}^{2}$ ), i.e. in the pollution plumes, and $12 \%$ lower for background values (IASI columns less than $2 \times 10^{18}$ molecules $/ \mathrm{cm}^{2}$ ). Part of these discrepancies could be explained by the different horizontal resolution of the instruments $(22 \mathrm{~km} \times 22 \mathrm{~km}$ for MOPITT and $12 \mathrm{~km}$ diameter for IASI), especially above inhomogeneous scenes. Note also that MOPITT observations in the bulk of the plume were generally rejected during the data processing (no retrieval), either because the cloud detection has mistaken large aerosol loadings with cloud-contaminated data or due to specific problems in the processing that filters out some high $\mathrm{CO}$ values. A new version of the MOPITT retrieval algorithm is currently being developed at NCAR in order to reduce the apparent high bias (between 5 and $7 \%$ on the total column) of the background retrievals, already established by comparisons with in situ observations (Emmons et al., 2007), and improve retrieval within high pollution plumes (M. Deeter, personal communication, 2008). 


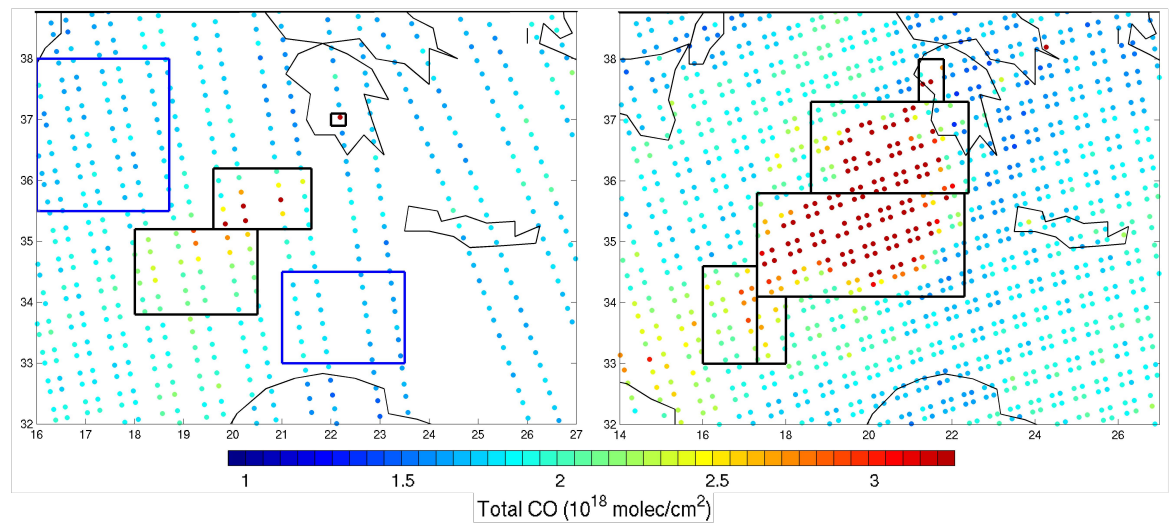

Fig. 7. IASI nighttime total CO retrievals for two days during the fire event: on 23 August 2007, at the beginning of the fire event (left), and on the 25th, after the most intense burning (right). The black boxes show the areas in which the CO burden related to the fires has been calculated, and the blue boxes on the 23rd show the area used to determine the average background value (CO column without the fires).

In spite of the additional difficulty associated with the retrievals in highly polluted wildfire plumes and the lack of validation data, the quality of our retrieval is reliable enough to allow a qualitative analysis above fires and quantitative analysis in fresh plumes and further downwind. In the following sections, we explore the information provided by IASI on the emissions and the long range transport of pollution above the Mediterranean associated with these large Greek fires.

\subsection{Top-down information on CO emissions}

The purpose of this section is to compare our observations of the additional $\mathrm{CO}$ burden to currently available processbased bottom-up inventories. The MODIS fire detection shows that most fires burned during approximately 7 days, starting on 23 until 30 August 2007. We calculate the CO emitted by the fires by evaluating the $\mathrm{CO}$ burden above background in the main fire plumes, directly after the largest fires in the Peloponnese. This simplified method can be applied in good approximation because strong North-Easterly wind rapidly exported the emitted pollution across the sea towards North Africa. We calculate the CO burden using the nighttime observations, since the most intense fire plumes are observed in the evening. We can then assume that the plume observed by IASI in the evening over the sea corresponds to emissions during the previous day only. The background total $\mathrm{CO}$ value is calculated in regions that should not be affected by the Greek fires, above the Mediterranean at the beginning of the fire event on 23 August. Figure 7 shows the areas considered as background and fire plume for the 23th (beginning of the fires) and the 25th (major burning). Since winds weakened at the end of the period, plumes closer to the fires are considered.

We estimate a total burden of $0.321 \mathrm{TgCO}$. The background may be over-evaluated, but this effect will be compensated by the lack of sensitivity of the IASI observation in the boundary layer. This is likely to result in underestimated total $\mathrm{CO}$, so that the value inferred here should be on the low end of the actual $\mathrm{CO}$ emissions. According to the EDGAR FT 2000 anthropogenic emission inventory, the total anthropogenic emissions over this region is $\sim 0.8 \mathrm{Tg} \mathrm{CO}$ per year. This contribution should be included in our background value. We thus assume that most of the derived burden is due to the large fires. This fire event would then correspond, in terms of pollution emitted, to $40 \%$ of the total annual anthropogenic activities in only 7 days. The widely used GFED inventory (version 2, van der Werf et al., 2006) gives a total of $0.247 \mathrm{Tg} \mathrm{CO}$ emitted by biomass burning in Greece during August 2007, 23\% lower compared to the CO burden derived from the IASI observations. We recalculated the total emissions from the Greek fires using a bottom-up approach based on an estimated total of $1700 \mathrm{~km}^{2}$ burned (EFFIS reported area for the Peloponnese) distributed at the location of the fires based on the MODIS fire detection. Therefore, the total area burned was multiplied by the fuels loading (scaled by the burning efficiencies, A. Mieville, personal communication, 2008) depending on vegetation type on a $0.5^{\circ} \times 0.5^{\circ}$ grid (here from the GLC2000 vegetation types, Bartholomé and Belward, 2005), and by the corresponding CO emission factors (Andreae and Merlet, 2001). Using this method, with average fuel loads of $1.8 \mathrm{~kg}$ dry matter $(\mathrm{DM}) / \mathrm{m}^{2}$ (standard deviation of $1.2 \mathrm{~kg} \mathrm{DM} / \mathrm{m}^{2}$ ) burned and emission factor of $64.7 \mathrm{~g} \mathrm{CO} / \mathrm{kg} \mathrm{DM}$ (standard deviation of $27.1 \mathrm{~g} \mathrm{CO} / \mathrm{kg} \mathrm{DM}$ ) in the region of the fires, we derive a total of $0.348 \mathrm{Tg} \mathrm{CO}, 8 \%$ larger compared to the IASI CO burden, $41 \%$ larger compared to the GFED total.

In this case study, the direct use of the IASI retrieved CO observations allows a preliminary analysis of the emissions. Although an accurate evaluation would require inverse modeling using a full chemistry and transport model, this already highlights the large uncertainties associated with the calculation of fire emissions. The Mediterranean region is often 
affected by large wildfires but the associated emissions are not always included in air quality models. In situ observations of trace gases and aerosols close to those fires would greatly improve assessments of their local and regional impact.

\subsection{Long range transport of pollution in August 2007: correlation between trace gases and aerosols mea- sured from space}

The last week of August 2007 was characterized by a low pressure area centered above Turkey and a strong anticyclone, centered above the Tyrrhenian Sea on 25 August, moving South-Eastwards and weakening in the following days. This resulted in strong North-Easterly winds above Greece. In addition to efficiently stirring the fires and increasing fire propagation, these strong winds rapidly exported the emitted pollution towards the South-West. On the 27th, a small low pressure area formed south of the Peloponnese, deviating towards the East the main circulation pattern.

The total CO columns observed by IASI directly reflect the advection of the fire emissions around the high pressure area. Figures 8-9 show the total $\mathrm{CO}$ distributions (filtered) for both daytime and nighttime observations from 23 to 30 August. Emissions from the large fires in the Peloponnese are rapidly (in less than one day) transported across the Mediterranean towards North Africa (Libya and Tunisia). The fire plume is then transported across North Africa around the high pressure system, recirculating to the Mediterranean basin over Algeria. At the end of August, recirculation from the Greek fire mix with local emissions from intense Algerian fires, transported to the North-East towards Italy.

The CO transport observed by IASI is consistent with the aerosol optical depths (fraction due to fine mode particles only) retrieved from the MODIS instrument (Fig. 10) during the day (Tanré et al., 1997). We use observations from both Terra and Aqua satellites, which have equator crossing time equal to 10:30 a.m. and 01:30 p.m., respectively, in order to have better horizontal coverage. The aerosol level 2 products (version 5), given at $10 \times 10 \mathrm{~km}$ horizontal resolution, are merged and averaged over a $0.2^{\circ} \times 0.2^{\circ}$ grid. Correlation coefficients between the two distributions over the sea during the fire event vary between $\sim 0.5$ on the 25 and $\sim 0.8$ the following days if we compare IASI and MODIS/Terra only (closer overpass times). These results are consistent with previous analysis by McMillan et al. (2008) which show that correlations are larger downwind from the emission region, probably due to the lack of sensitivity of thermal IR instruments to the surface layers which results in a low bias close to the emissions. These correlations may provide insight into the emission ratios within the fire plume and the respective lifetimes of trace gases and aerosols (Edwards et al., 2006). However, such study is difficult for the region analyzed here due to large uncertainties over deserts for both observations.
In order to evaluate the information on plume height provided by IASI, we compare the retrieved $\mathrm{CO}$ vertical profiles with the available CALIOP lidar observations on board the CALIPSO satellite. Only two CALIPSO overpasses showed signatures from the Greek fires (other satellite tracks during this time period where too far from the fires), one crossing the fire plume above the Mediterranean on 25 August 2007 (Fig. 8) and the other above North Africa on 26 August 2007 (Fig. 8). Figure 11 shows the CALIOP $532 \mathrm{~nm}$ total attenuated backscatter coefficients (level 1 version 2 data) (Winker et al., 2003) averaged over these two regions (between $34.64^{\circ} \mathrm{N}$ and $35.71^{\circ} \mathrm{N}$ along the CALIPSO track on the 25 th; between $31.78^{\circ} \mathrm{N}$ and $32.32^{\circ} \mathrm{N}$ along the track on the 26th), and every $60 \mathrm{~m}$ on the vertical. Clear aerosol signals are observed around $1-3 \mathrm{~km}$, with backscatter coefficients $\sim 4 \times 10^{-6} \mathrm{~m}^{-1} \mathrm{sr}^{-1}$, of the same order of magnitude as other events detected by surface lidar observations from the EARLINET network in June 2007 in Athens (Papayannis et al., 2008). Since IASI and CALIOP do not have the same overpass times (CALIPSO overpass a few minutes after AQUA), we have chosen to use trajectory calculations to account for transport and allow the comparison of the same air masses. Therefore, forward and backward trajectories from the aerosol plume observed by CALIOP were computed using the FLEXPART Lagrangian particle dispersion model (Stohl et al., 1998, 2002, 2005) with ECMWF meteorological fields (with resolution $1.125^{\circ} \times 1.125^{\circ}, 6 \mathrm{~h}$ ). Large numbers of particles are released and transported, allowing the estimation of the air masses dispersion. The expected location of the air masses detected by CALIPSO at the IASI overpass time is shown in Fig. 8 (boxes). The corresponding average IASI CO profiles for nighttime and daytime observations are shown in Fig. 11. On the 26th, only the nighttime $\mathrm{CO}$ profile is shown as the daytime retrievals are removed by the RMS filter. The profiles retrieved at the location of the CALIOP plume (without transport) and in background conditions are also plotted for reference.

The low vertical resolution of the IASI CO profiles does obviously not allow the precise location of the altitude of the plume but the large $\mathrm{CO}$ enhancements observed in the lower troposphere are consistent with the enhanced aerosol extinction. On 25 August, accounting for transport lowers nighttime $\mathrm{CO}$ and increases daytime $\mathrm{CO}$, reconciling the order of magnitude of both measurements. On the contrary, accounting for transport increases $\mathrm{CO}$ on the 26th. A small secondary peak ( $\sim 170 \mathrm{ppbv})$ is observed around $5 \mathrm{~km}$, which could correspond to the aerosol enhancement at the same level. Retrievals in background conditions show maximum $\mathrm{CO}$ in the middle troposphere, further highlighting the capabilities of our retrieval to depart from the a priori profile, even close to the surface. In spite of the lack of vertical resolution, the retrieved $\mathrm{CO}$ profiles thus seem to provide useful information on the vertical level of the transport (lower, middle or upper troposphere). 

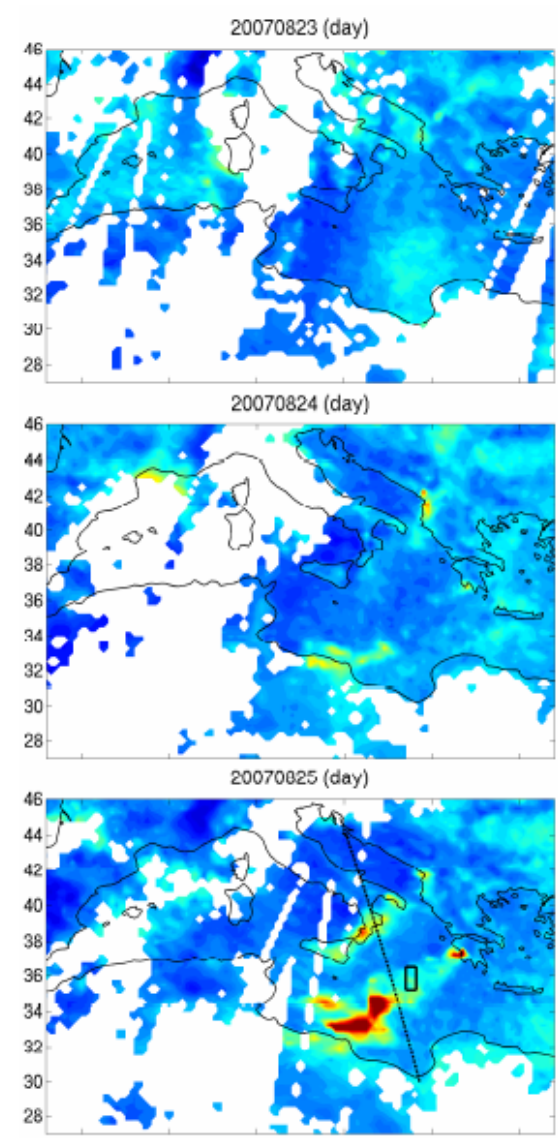

20070826 (day)

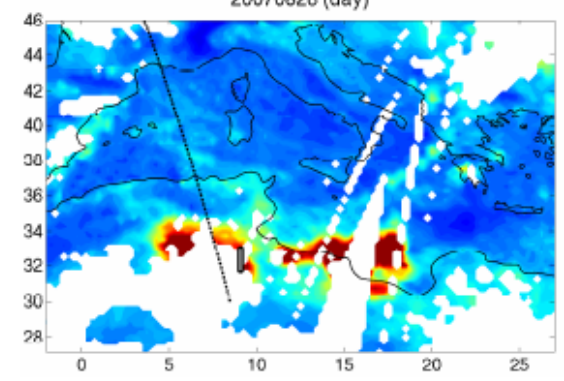

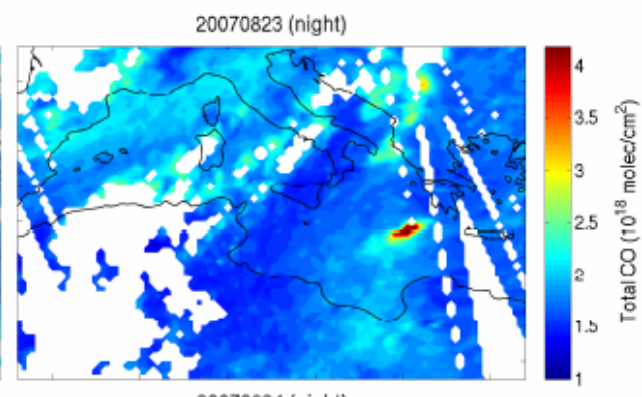

20070824 (night)

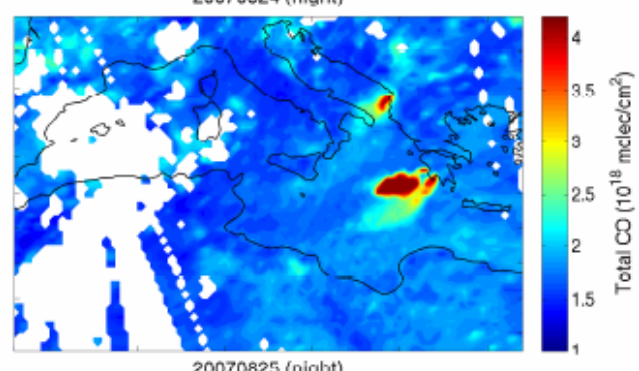

20070825 (night)

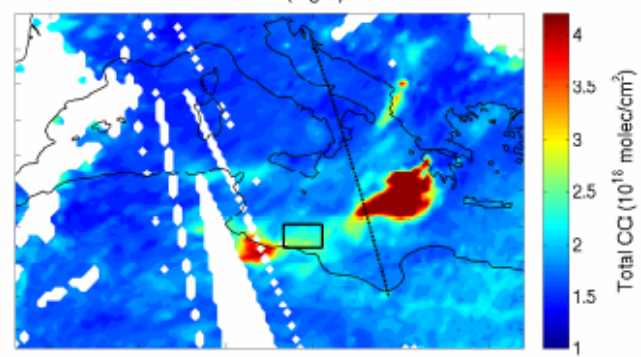

20070826 (night)

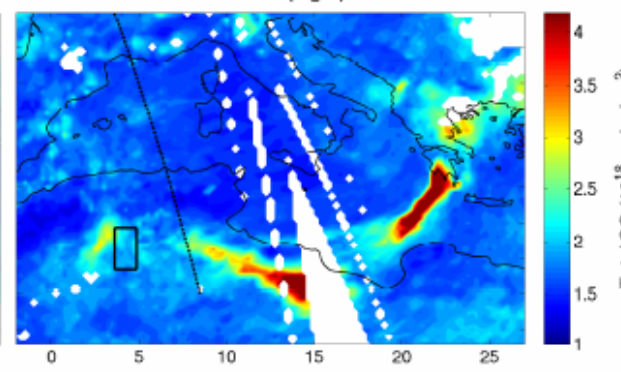

Fig. 8. IASI daytime (left) and nighttime (right) total column CO retrievals during the Greek fires event (23-26 August 2007), interpolated on a $0.2^{\circ} \times 0.2^{\circ}$ grid after application of the RMS filter (see text for detail). When available in the region of the fires (25 and 26 August 2007), the CALIPSO satellite track is indicated by a black dashed line, with the associated boxes used for the comparisons between IASI and CALIPSO with transport correction.

Figure 12 shows a vertical cross-section across the main plume as observed by IASI on the 25 during the night. The cross-section reflects emission variability in the fire activity and subsequent transport. The same general features are observed for the other days. Close to the fires, the profiles indicate large $\mathrm{CO}$ enhancements up to $4 \mathrm{~km}$, with lower mixing ratios close to the surface at night. Since the CO profiles exhibit a maximum at the surface during the day, this decrease could be due to the low sensitivity to the first levels at night (Sect. 3.2). However, these profiles, with a maximum $\mathrm{CO}$ in the $1-2 \mathrm{~km}$ layer, are characterized by approximately the same averaging kernels as the profiles further downwind with largest $\mathrm{CO}$ in the two lower levels (see also Fig. 3, nighttime profile in fire plume). This slight subsidence after the Peloponnese is also visible on the cross sections. Since retrievals were done in similar conditions, this maximum at $2 \mathrm{~km}$ could correspond to a real feature of the $\mathrm{CO}$ profile. The differences could then be due to variability in the fire activity, or to a subsidence of the plume during the transport. A transport around $2 \mathrm{~km}$ is also consistent with the CALIOP profiles.

The cross sections show that the fire plume is then transported in the lower troposphere towards the Libyan coast. 

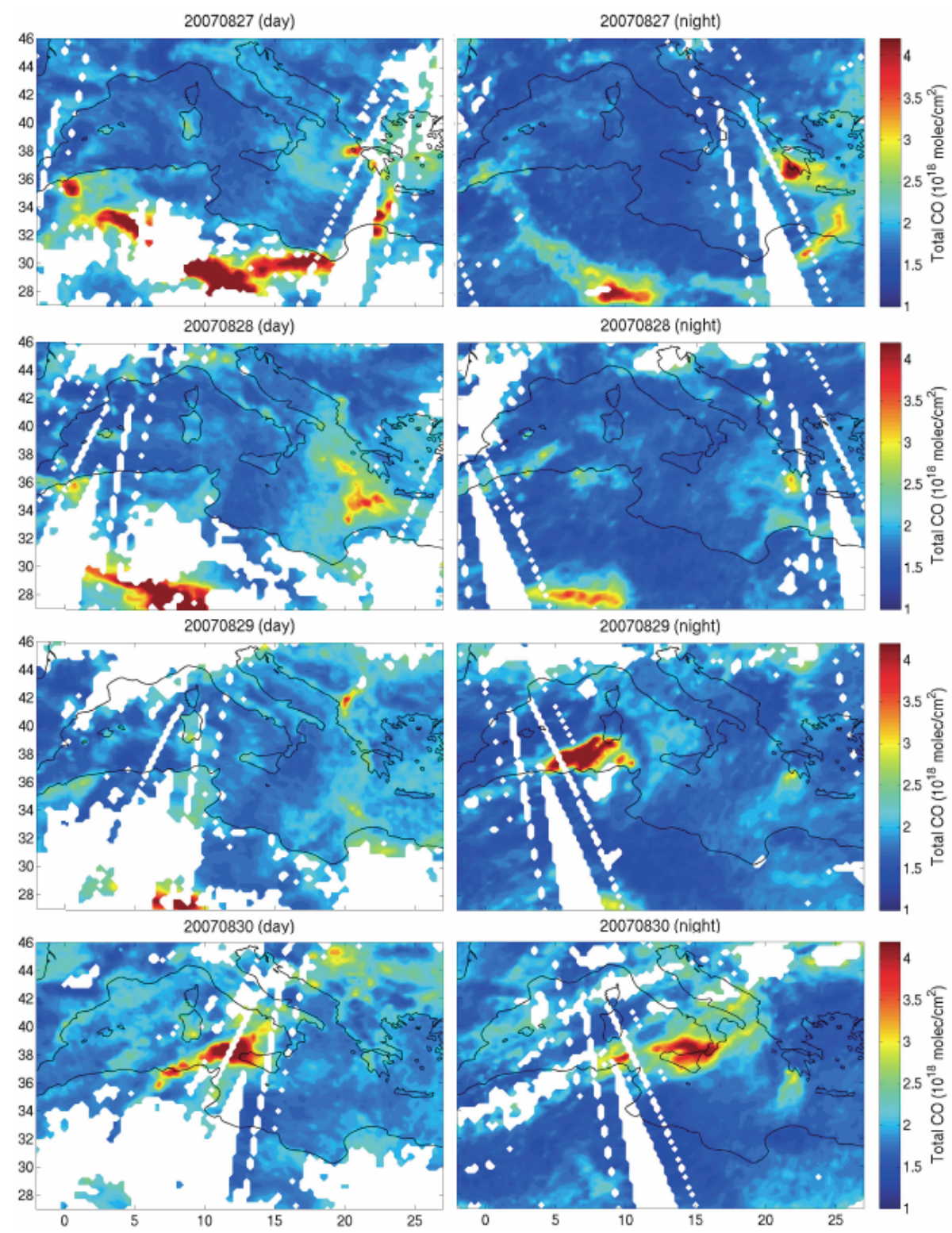

Fig. 9. Same as Fig. 8, for 27-30 August 2007.

The plume seems to be uplifted above the continent and transported in the mid-troposphere: maximum at $\sim 2-3 \mathrm{~km}$ on the 26 from emissions on 25 August, reaching $4-5 \mathrm{~km}$ on the 27th from emissions on 26 August above North Africa according to the nighttime observations (most retrievals are filtered during the day in this region).

According to FLEXPART, the transport of the fire plume is confined to the lower troposphere with a transport at constant level across the sea, followed by a slight uplift over Algeria for some particles. However, the increasing altitude of the plume over Libya is not reproduced in the trajectories. This feature could in fact be due to the increasing boundary layer height over this region (up to $2 \mathrm{~km}$ while it is barely $\sim 300 \mathrm{~m}$ above the sea) which could lower the sensitivity of
IASI to the lower troposphere. Indeed, a relative decrease of the DOFS and the contribution of the lower levels to this DOFS in this region can be observed on Fig. 3.

On 30 August, large $\mathrm{CO}$ enhancements associated with the Algerian fires are observed: up to $900 \mathrm{ppbv}$ at the surface close to the coast, with an ascending tendency towards the sea and a transport at $\sim 2-3 \mathrm{~km}$ towards Italy. This uplift is in good agreement with the trajectory calculations.

\section{Conclusions}

In this paper, we evaluated the quality of the $\mathrm{CO}$ distributions retrieved from the IASI spectra under highly polluted 


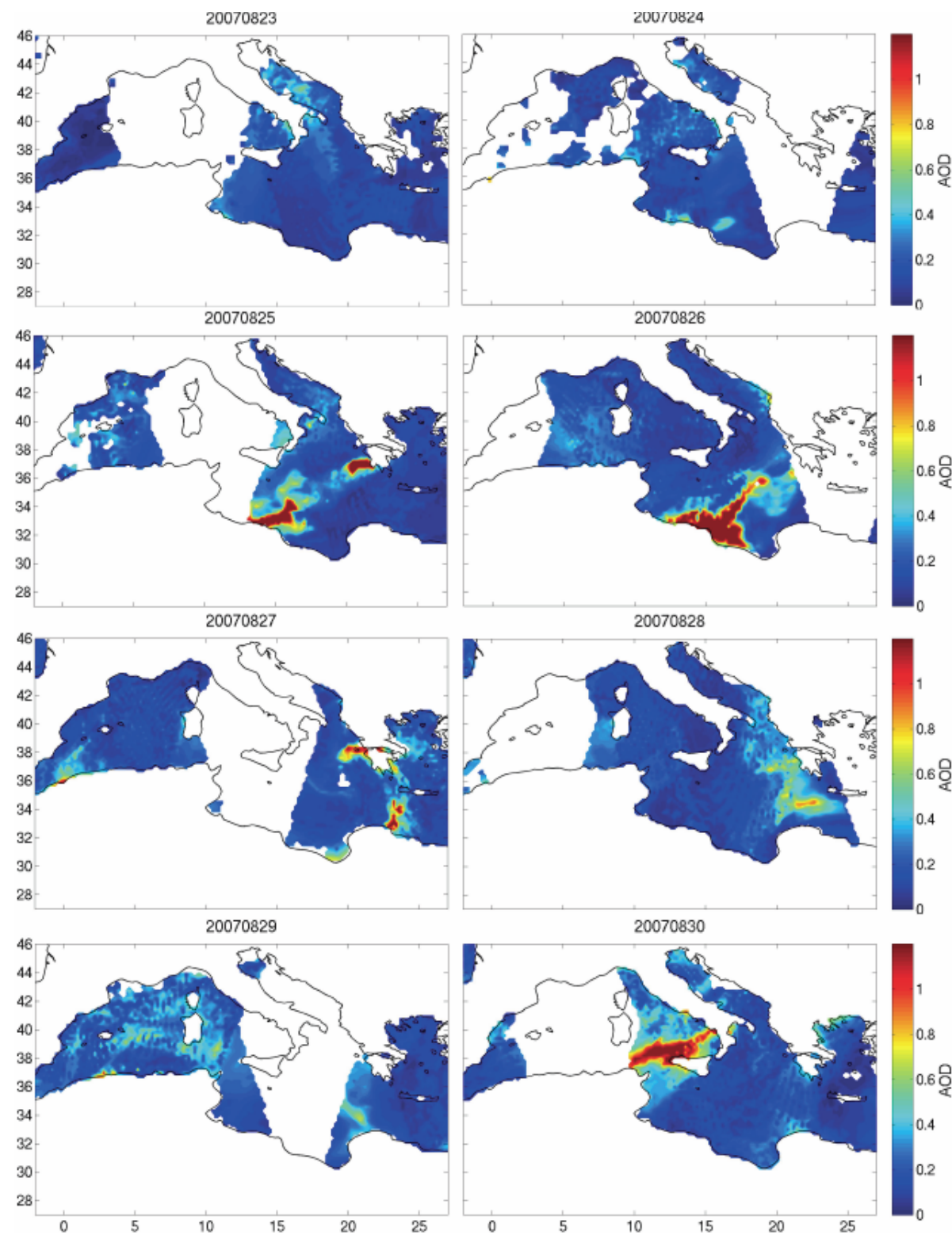

Fig. 10. Fine mode AOD retrieved from the MODIS/Terra and AQUA observations (averaged over a $0.2^{\circ} \times 0.2^{\circ}$ grid) for $23-30$ August 2007.

conditions resulting from wildfires. We focused our analysis on the record-breaking fires which burned more than $1700 \mathrm{~km}^{2}$ in Greece in only one week at the end of $\mathrm{Au}-$ gust 2007. The CO retrievals were undertaken using the Fast Optimal Retrievals on Layers for IASI (FORLI) algorithm, based on the optimal estimation method (OEM). Large CO enhancements were obtained above the Central Mediterranean Basin, traveling from the fires in the Peloponnese across the sea towards North Africa. CO total columns up to $24 \times 10^{18}$ molecules $/ \mathrm{cm}^{2}$ and absolute volume mixing ratio up to $4 \mathrm{ppmv}$ are retrieved in the fire plume off the Greek coast on the 25 August. On the same day, up to $30 \times 10^{18}$ molecules $/ \mathrm{cm}^{2}$ and $22 \mathrm{ppmv}$ (more than one hun- dred times larger than the background levels) in the lower troposphere are retrieved close to the fires above the Peloponnese, but with larger uncertainty (larger residual between observed and simulated spectra). The information content was analyzed using the averaging kernels and the calculated degrees of freedom for signal (DOFS). The maximum sensitivity is reached in the free troposphere around $5 \mathrm{~km}$ and the vertical resolution is estimated to be $8 \mathrm{~km}$. The DOFS depend mostly on the thermal contrast and vary between $\sim 1.6$ over the sea and $\sim 1.8$ over land during the day (reaching more than 2 above hot surfaces). However, this improved sensitivity over land does not always apply directly above fires. Under extreme pollution cases, the averaging kernels show little 

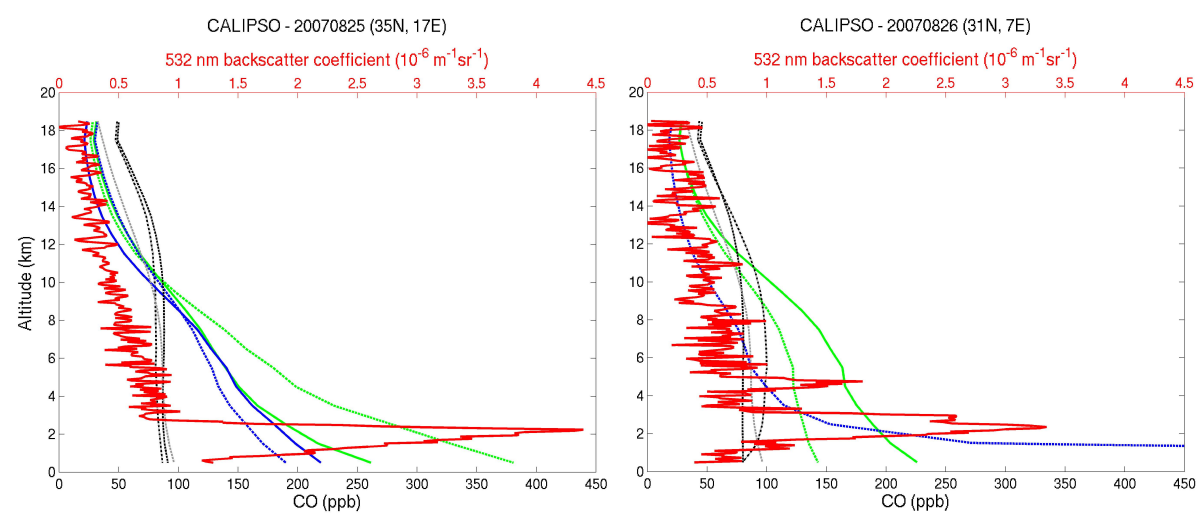

Fig. 11. Comparison for 25 and 26 August 2007 between CALIPSO backscatter coefficient profiles with enhanced aerosol layers in the region of the Greek fire plume and both daytime and nighttime IASI CO profile retrievals for: the average profile collocated with the CALIPSO data, and the CO profile accounting for transport (see text for details). The IASI a priori profiles and retrievals corresponding to background levels (over the western part of the Mediterranean basin on 25 August, and on the eastern part on 26 August) are also shown for reference.
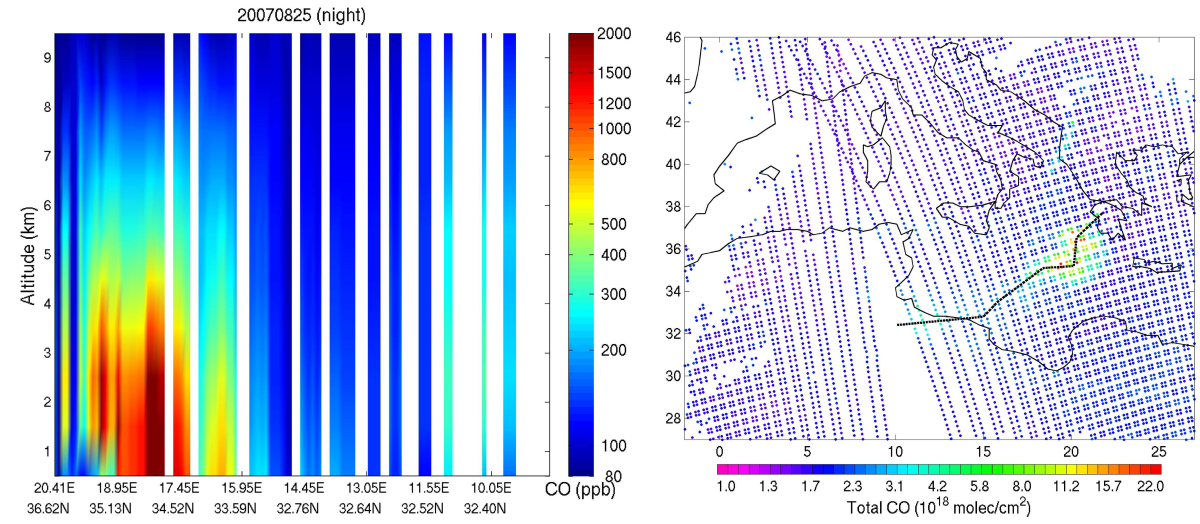

Fig. 12. IASI nighttime vertical profiles (left panel in log scale) along the plume on 25 August 2007. The corresponding latitude and longitude coordinates are indicated on the $\mathrm{x}$-axis. The corresponding location of the cross section is plotted on top of the total CO retrievals (log scale) for the same day on the right panel.

sensitivity below $\sim 2 \mathrm{~km}$ which probably results from a combination of several factors: enhanced vertical mixing above the fires could lower the thermal contrast; the temperature and humidity profiles may be subject to larger uncertainties close to the fires; and the large aerosol concentrations could impact the quality of the retrieval. These uncertainties are difficult to quantify due to the lack of independent observations. Saturation of the $\mathrm{CO}$ lines does not seem to be the limiting factor for this case.

The quality of the retrievals was further evaluated using the RMS error on the final adjustment of the spectra (RMS of the residuals). Filtering out the largest errors above desert, the average RMS is $2.02 \times 10^{-9} \mathrm{~W} /\left(\mathrm{cm}^{2} \mathrm{~cm}^{-1} \mathrm{sr}\right)$ and is slightly increasing (by $\sim 14 \%$ ) in the fresh fire plumes. This highlights larger uncertainty in the fire plumes than in background conditions. However, the RMS remains reasonably close the expected radiometric noise $\left(2.00 \times 10^{-9} \mathrm{~W} /\left(\mathrm{cm}^{2} \mathrm{~cm}^{-1} \mathrm{sr}\right)\right)$, allowing quantita- tive use of the observations. Above fires, RMS above $3.00 \times 10^{-9} \mathrm{~W} /\left(\mathrm{cm}^{2} \mathrm{~cm}^{-1} \mathrm{sr}\right)$ were found, the corresponding retrieval should therefore be used with caution (qualitative use only recommended). Among the different hypothesis tested, one of the main contributions to these larger residuals could be inhomogeneities within the IASI pixels (diameter of $12 \mathrm{~km}$ ), which should be further analyzed. Validation based on in situ profiles would however be required for a quantitative evaluation of the uncertainty on the $\mathrm{CO}$ retrievals. In particular, the impact of small scale variation on the retrievals should be further studied to better understand its importance in different situations (fires, urban pollution, etc.).

Using the retrieved total $\mathrm{CO}$ in the fire plumes and removing the contribution from background levels, we estimated a $\mathrm{CO}$ burden due to the Greek fires to $0.321 \mathrm{Tg}$, i.e. $\sim 40 \%$ of the total annual anthropogenic emissions in Greece (according to the EDGAR FT 2000 inventory). This is 23\% larger than the emissions from the state-of-the-art GFED inventory 
for August 2007 in this region, and 8\% lower than a calculation based on the total area burned in the Peloponnese during this fire event only. In addition to highlighting uncertainties in the calculation of fire emissions, this comparison further verifies that the large enhancements observed by IASI are of a correct order of magnitude.

The information provided on the long-range transport of pollution associated with this event was studied through comparisons to aerosol measurements. For the fire event, the total columns of $\mathrm{CO}$ were well correlated with the MODIS (Terra and Aqua) AOD, showing rapid transport of trace gases and aerosols across the Mediterranean and North Africa (less than one day to cross the sea from Greece to Libya). The $\mathrm{CO}$ profiles indicate a transport at low altitude, with larger enhancements in the lower troposphere. We verified this through comparisons with the CALIOP lidar measurements on board the CALIPSO satellite during the same time period. Although the CALIPSO track did not cross the main fire plumes as seen by IASI and MODIS, enhancements in the backscatter coefficient were clearly visible along the plume export pathway, at about $2 \mathrm{~km}$. Comparisons with the IASI CO retrievals, accounting for transport using FLEXPART trajectories, show that these correspond to $\mathrm{CO}$ levels above background with larger values below $4 \mathrm{~km}$, in the lower troposphere. We concluded that, although the vertical resolution does not allow precise location of the fire plume, the general level can be identified (upper/middle or lower troposphere). This information would be very valuable for the evaluation of the fire injection heights in the chemistry and transport models. Apparent evolution of the plume height in the retrievals should however always be confronted to sensitivity profiles (averaging kernels) and critical meteorological parameters such as surface temperature and boundary layer height.

Further analysis of the FLEXPART and the vertical aerosol profiles of CALIPSO is currently undertaken in order to investigate the radiative impacts of these biomass burning plumes. Analysis of the IASI data in conjunction with a chemistry-transport model will allow further understanding of the information content of the $\mathrm{CO}$ retrieval as well as an evaluation of the impact on atmospheric chemistry of these large fires on regional air quality, and in particular on ozone production. The simultaneous IASI observation of $\mathrm{CO}$ and ozone (Turquety et al., 2004; Eremenko et al., 2008; Boynard et al., 2009; Keim et al., 2009) with shorter lived species, among which $\mathrm{NH}_{3}$ and several volatile organic compounds (Coheur et al., 2009) will also provide insight onto the fast chemical processes occurring in the fire plumes. Further correlation analysis between trace gases and aerosol measurements will also allow the study of the interactions between aerosols and photochemistry in the fire plumes.

Acknowledgements. IASI has been developed and built under the responsibility of the Centre National d'Etudes Spatiales (CNES, France). It is flown onboard the Metop satellites as part of the
EUMETSAT Polar System. The IASI L1C data are received through the EUMETCast near real time data distribution service. The authors acknowledge the French atmospheric database Ether (http://ether.ipsl.jussieu.fr) for providing the IASI data, as well as the French ICARE database (http://www.icare.univ-lille1.fr/) for providing the MODIS and CALIPSO data. The MODIS and CALIPSO project and science teams are greatly acknowledged for data availability. We thank A. Stohl for the availability of the FLEXPART model. The European Centre for Medium Range Weather Forecast (ECMWF) is acknowledged for the meteorological data used in the retrieval algorithm and in the FLEXPART simulations. The authors also thank F. Ravetta for helpful discussions. S. Turquety and C. Clerbaux are grateful to CNES for financial support. The research in Belgium was funded by the F.R.S.-FNRS (M.I.S. nF.4511.08), the Belgian State Federal Office for Scientific, Technical and Cultural Affairs and the European Space Agency (ESA-Prodex arrangements C90-327). Financial support by the "Communauté française de Belgique Actions de Recherche Concertées" is also acknowledged. The authors are grateful to INSU for publication support.

Edited by: T. Wagner

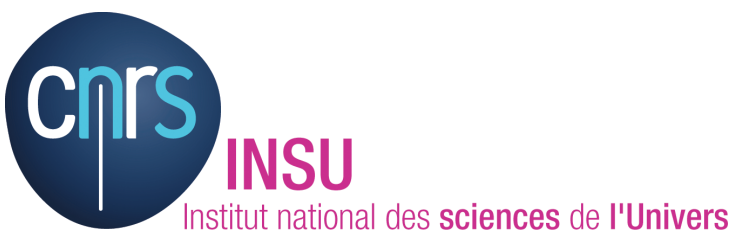

The publication of this article is financed by CNRS-INSU.

\section{References}

Andreae, M. O. and Merlet, P.: Emission of trace gases and aerosols from biomass burning, Global Biogeochem. Cy., 15(4), 955-966, 2001.

Arellano Jr., A. F., Kasibhatla, P. S., Giglio, L., van der Werf, G. R., Randerson, J. T., and Collatz, G. J.: Timedependent inversion estimates of global biomass-burning $\mathrm{CO}$ emissions using Measurement of Pollution in the Troposphere (MOPITT) measurements, J. Geophys. Res., 111, D09303, doi:10.1029/2005JD006613, 2006.

Arino, O., Plummer, S., and Casadio, S.: Fire Disturbance: the Twelve years time series of the ATSR World Fire Atlas, Proceedings of the ENVISAT Symposium 2007, SP-636, ESA, 2007.

Barret, B., Turquety, S., Hurtmans, D., Clerbaux, C., Hadji-Lazaro, J., Bey, I., Auvray, M., and Coheur, P.-F.: Global carbon monoxide vertical distributions from spaceborne high-resolution FTIR nadir measurements, Atmos. Chem. Phys., 5, 2901-2914, 2005, http://www.atmos-chem-phys.net/5/2901/2005/.

Bartholomé, E. and Belward, A. S., M GLC2000: a new approach to global land cover mapping from Earth observation data, Int. J. Remote Sens., 26(9), 1959-1977, doi:10.1080/01431160412331291297, 2005.

Boynard, A., Clerbaux, C., Coheur, P.-F., Hurtmans, D., Turquety, S., George, M., Hadji-Lazaro, J., Keim, C., and Meyer-Arnek, J. Measurements of total and tropospheric ozone from IASI: com- 
parison with correlative satellite and ozonesonde observations, Atmos. Chem. Phys. Discuss., 9, 10513-10548, 2009, http://www.atmos-chem-phys-discuss.net/9/10513/2009/.

Clerbaux, C., Coheur, P.-F., Hurtmans, D., Barret, B., Carleer, M., Colin, R., Semeniuk, K., McConnell, J. C., Boone, C., and Bernath, P.: Carbon monoxide distribution from the ACEFTS solar occultation measurements, Geophys. Res. Lett., 32, L16S01, doi:10.1029/2005GL022394, 2005.

Clerbaux, C., Boynard, A., Clarisse, L., George, M., Hadji-Lazaro, J., Herbin, H., Hurtmans, D., Pommier, M., Razavi, A., Turquety, S., Wespes, C., and Coheur, P.-F.: Monitoring of atmospheric composition using the thermal infrared IASI/MetOp sounder, Atmos. Chem. Phys. Discuss., 9, 8307-8339, 2009, http://www.atmos-chem-phys-discuss.net/9/8307/2009/.

Coheur, P.-F., Barret, B., Turquety, S., Hurtmans, D., Hadji-Lazaro, J., and Clerbaux, C.: Retrieval and characterization of ozone vertical profiles from a thermal infrared nadir sounder, J. Geophys. Res., 110, D24303, doi:10.1029/2005JD005845, 2005.

Coheur, P.-F., Clarisse, L., Turquety, S., Hurtmans, D., and Clerbaux, C.: IASI measurements of reactive trace species in biomass burning plumes, Atmos. Chem. Phys. Discuss., 9, 8757-8789, 2009 ,

http://www.atmos-chem-phys-discuss.net/9/8757/2009/.

Damoah, R., Spichtinger, N., Servranckx, R., Fromm, M., Eloranta, E. W., Razenkov, I. A., James, P., Shulski, M., Forster, C., and Stohl, A.: A case study of pyro-convection using transport model and remote sensing data, Atmos. Chem. Phys., 6, 173-185, 2006, http://www.atmos-chem-phys.net/6/173/2006/.

Deeter, M. N., Emmons, L. K., Francis, G. L., et al.: Operational carbon monoxide retrieval algorithm and selected results for the MOPITT instrument, J. Geophys. Res., 108(D14), 4399, doi:10.1029/2002JD003186, 2003.

Edwards, D. P., Emmons, L. K., Hauglustaine, D. A., et al.: Observations of carbon monoxide and aerosols from the Terra satellite: Northern Hemisphere variability, J. Geophys. Res., 109, D24202, doi:10.1029/2004JD004727, 2004.

Edwards, D. P., Emmons, L. K., Gille, J. C., et al.: Satelliteobserved pollution from Southern Hemisphere biomass burning, J. Geophys. Res., 111, D14312, doi:10.1029/2005JD006655, 2006.

EFFIS Forest Fires in Europe 2007 report, Annual fire report, European Forest Fire Information System, JRC, (http://effis.jrc.ec. europa.eu/reports/fire-reports), 2008.

Emmons, L. K., Pfister, G. G., Edwards, D. P., Gille, J.C., Sachse, G., Blake, D., Wofsy, S., Gerbig, C., Matross, D., and Nédélec, P.: Measurements of Pollution in the Troposphere (MOPITT) validation exercises during summer 2004 field campaigns over North America, J. Geophys. Res., 112, D12S02, doi:10.1029/2006JD007833, 2007.

Eremenko, M., Dufour, G., Foret, G., Keim, C., Orphal, J., Beekmann, M., Bergametti, G., and Flaud, J.-M.: Tropospheric ozone distributions over Europe during the heat wave in July 2007 observed from infrared nadir spectra recorded by IASI, Geophys. Res. Lett., 35, L18805, doi:10.1029/2008GL034803, 2008.

Fromm, M. D. and Servranckx, R.: Transport of forest fire smoke above the tropopause by supercell convection, Geophys. Res. Lett., 30(10), 1542, doi:10.1029/2002GL016820, 2003.

George, M., Clerbaux, C., Hurtmans, D., Turquety, S., Coheur, P.F., Pommier, M., Hadji-Lazaro, J., Edwards, D. P., Worden, H.,
Luo, M., Rinsland, C., and McMillan, W.: Carbon monoxide distributions from the IASI/METOP mission: evaluation with other space-borne remote sensors, Atmos. Chem. Phys. Discuss., 9, 9793-9822, 2009,

http://www.atmos-chem-phys-discuss.net/9/9793/2009/.

Giglio, L., van der Werf, G. R., Randerson, J. T., Collatz, G. J., and Kasibhatla, P.: Global estimation of burned area using MODIS active fire observations, Atmos. Chem. Phys., 6, 957-974, 2006, http://www.atmos-chem-phys.net/6/957/2006/.

Hadji-Lazaro, J., Clerbaux, C., Couvert, P., Chazette, P., and Boonne, C.: Cloud filter for $\mathrm{CO}$ retrieval from IMG infrared spectra using ECMWF temperatures and POLDER cloud data, Geophys. Res. Lett., 28(12), 2397-2400, 2001.

Henze, D. K., Seinfeld, J. H., Liao, W., Sandu, A., and Carmichael, G. R.: Inverse modeling of aerosol dynamics: Condensational growth, J. Geophys. Res., 109, D14201, doi:10.1029/2004JD004593, 2004.

Hobbs, P. V., Sinha, P., Yokelson, R. J., Christian, T. J., Blake, D. R., Gao, S., Kirchstetter, T. W., Novakov, T., and Pilewskie, P.: Evolution of gases and particles from a savanna fire in South Africa, J. Geophys. Res., 108(D13), 8485, doi:10.1029/2002JD002352, 2003.

Justice, C. O., Giglio, L., Korontzi, S., Owens, J., Morisette, J., Roy, D., Descloitres, J., Alleaume, S., Petitcolin, F., and Kaufman, Y.: The MODIS fire products, Remote Sens. Environ., 83, 244-262, 2002.

Kasischke E. S. and Penner, J. E.: Improving global estimates of atmospheric emissions from biomass burning, J. Geophys. Res., 109, D14S01, doi:10.1029/2004JD004972, 2004.

Kasischke, E. S., Hyer, E. J., Novelli, P. C., Bruhwiler, L. P., French, N. H. F., Sukhinin, A. I., Hewson, J. H., and Stocks, B. J.: Influences of boreal fire emissions on Northern Hemisphere atmospheric carbon and carbon monoxide, Global Biogeochem. Cy., 19, GB1012, doi:10.1029/2004GB002300, 2005.

Keim, C., Eremenko, M., Orphal, J., Dufour, G., Flaud, J.-M., Höpfner, M., Boynard, A., Clerbaux, C., Payan, S., Coheur, P.F., Hurtmans, D., Claude, H., Dier, H., Johnson, B., Kelder, H., Kivi, R., Koide, T., López Bartolomé, M., Lambkin, K., Moore, D., Schmidlin, F. J., and Stübi, R.: Tropospheric ozone from IASI: comparison of different inversion algorithms and validation with ozone sondes in the northern middle latitudes, Atmos. Chem. Phys. Discuss., 9, 11441-11479, 2009,

http://www.atmos-chem-phys-discuss.net/9/11441/2009/.

Lamarque, J.-F., Edwards, D. P., Emmons, L. K., et al.: Identification of CO plumes from MOPITT data: application to the August 2000 Idaho-Montana forest fires, Geophys. Res. Lett., 30(13), 1688, doi:10.1029/2003GL017503, 2003.

McMillan, W. W., Warner, J. X., McCourt Comer, M., et al.: AIRS views transport from 12 to 22 July 2004 Alaskan/Canadian fires: Correlation of AIRS CO and MODIS AOD with forward trajectories and comparison of AIRS CO retrievals with DC-8 in situ measurements during INTEX-A/ICARTT, J. Geophys. Res., 113, D20301, doi:10.1029/2007JD009711, 2008.

Meehl, G. A. and Tebaldi, C.: More intense, more frequent, and longer lasting heat waves in the 21 st century, Science, 305, 5686, 994-997, 2004.

Nedelec, P., Cammas, J.-P., Thouret, V., Athier, G., Cousin, J.-M., Legrand, C., Abonnel, C., Lecoeur, F., Cayez, G., and Marizy, C.: An improved infrared carbon monoxide analyser for routine 
measurements aboard commercial Airbus aircraft: technical validation and first scientific results of the MOZAIC III programme, Atmos. Chem. Phys., 3, 1551-1564, 2003, http://www.atmos-chem-phys.net/3/1551/2003/.

Olivier, J. G. J. and Berdowski, J. J. M.: Global emissions sources and sinks, in: The Climate System, edited by: Berdowski, J., Guicherit, R., and Heij, B. J., A.A. Balkema Publishers/Swets \& Zeitlinger Publishers, Lisse, The Netherlands, 33-78, ISBN 90 5809255 0, 2001.

Papayannis, A., Mamouri, R. E., Tsaknakis, G., et al.: Optical, microphysical and chemical properties of tropospheric aerosols retrieved by a 6-wavelength raman lidar system during a biomass burning event over Athens, Greece: Proceeding of the 24th International laser radar conference, 2008.

Pfister, G., Hess, P., Emmons, L., Lamarque, J.-F., Wiedenmyer, C., Edwards, D., Pétron, G., Gille, J., and Sachse, G.: Constraints on emissions for the Alaskan wildfires 2004 using data assimilation and inverse modeling of MOPITT CO, Geophys. Res. Lett., 32, L11809, doi:10.1029/2005GL022995, 2005.

Rodgers, C. D.: Inverse Methods for Atmospheric Sounding: Theory and Practice, Atmos. Ocean. Planet. Phys., 2, 238 pp., World Sci., River Edge, NJ, 2000.

Schär, C., Vidale, P. L., Lüthi, D., Frei, C., Häberli, C., Liniger, M. A., and Appenzeller, C.: The role of increasing temperature variability in European summer heatwaves, Nature 427(6972), 332-336, 2004.

Stohl, A., Hittenberger, M., and Wotawa, G.: Validation of the Lagrangian particle dispersion model FLEXPART against large scale tracer experiment data, Atmos. Environ., 32, 4245-4264, 1998.

Stohl, A., Eckhardt, S., Forster, C., James, P., Spichtinger, N., and Seibert, P.: A replacement for simple backtrajectory calculations in the interpretation of atmospheric trace substance measurements, Atmos. Environ., 36, 4635-4648, 2002.

Stohl, A., Forster, C., Frank, A., Seibert, P., and Wotawa, G.: Technical Note: The Lagrangian particle dispersion model FLEXPART version 6.2, Atmos. Chem. Phys., 5, 2461-2474, 2005, http://www.atmos-chem-phys.net/5/2461/2005/.

Szopa, S., Hauglustaine, D. A., and Ciais, P.: Relative contributions of biomass burning emissions and atmospheric transport to carbon monoxide interannual variability, Geophys. Res. Lett., 34, L18810, doi:10.1029/2007GL030231, 2007.
Tanré, D., Kaufman, Y. J., Herman, M., and Mattoo, S.: Remote sensing of aerosol over oceans from EOS-MODIS, J. Geophys. Res., 102, 16971-16988, 1997.

Turquety, S., Clerbaux, C., Law, K., Coheur, P.-F., Cozic, A., Szopa, S., Hauglustaine, D. A., Hadji-Lazaro, J., Gloudemans, A. M. S., Schrijver, H., Boone, C. D., Bernath, P. F., and Edwards, D. P.: CO emission and export from Asia: an analysis combining complementary satellite measurements (MOPITT, SCIAMACHY and ACE-FTS) with global modeling, Atmos. Chem. Phys., 8, 5187-5204, 2008, http://www.atmos-chem-phys.net/8/5187/2008/.

Turquety, S., Logan, J. A., Jacob, D. J., Hudman, R. C., Leung, F. Y., Heald, C. L., Yantosca, R. M., Wu, S., Emmons, L. K., Edwards, D. P., and Sachse, G. W.: Inventory of boreal fire emissions for North America in 2004: the importance of peat burning and pyro-convective injection, J. Geophys. Res., 112, D12S03, doi:10.1029/2006JD007281, 2007.

Turquety, S., Hadji-Lazaro, J., Clerbaux, C., Hauglustaine, D. A., Clough, S. A., Cassé, V., Shlüssel, P., and Mégie, G.: Operational trace gas retrieval algorithm for the Infrared Atmospheric Sounding Interferometer, J. Geophys. Res., 109, D21301, doi:10.1029/2004JD00482, 2004.

van der Werf, G. R., Randerson, J. T., Giglio, L., Collatz, G. J., Kasibhatla, P. S., and Arellano Jr., A. F.: Interannual variability in global biomass burning emissions from 1997 to 2004, Atmos. Chem. Phys., 6, 3423-3441, 2006, http://www.atmos-chem-phys.net/6/3423/2006/.

Wan, Z.: New refinements and validation of the MODIS LandSurface Temperature/Emissivity products, Remote Sens. Environ., 112, 59-74, 2008.

Winker, D. M., Pelon, J., and McCormick, M. P.: The CALIPSO mission: Spaceborne lidar for observation of aerosols and clouds, Proc. SPIE, 4893, 1-11, 2003.

Wotawa, G., Novelli, P., Trainer, M., and Granier, C.: Inter-Annual Variability of Summertime CO Concentrations in the Northern Hemisphere Explained by Boreal Forest Fires in North America and Russia, Geophys. Res. Lett., 28(24), 4575-4578, 2001.

Yurganov, L. N., McMillan, W. W., Dzhola, A. V., Grechko, E. I., Jones, N. B., and van der Werf, G. R.: Global AIRS and MOPITT CO measurements: Validation, comparison, and links to biomass burning variations and carbon cycle, J. Geophys. Res., 113, D09301, doi:10.1029/2007JD009229, 2008. 